\title{
Subunit-Dependent High-Affinity Zinc Inhibition of Acid-Sensing Ion Channels
}

\author{
Xiang-Ping Chu, ${ }_{1}^{1}$ John A. Wemmie, ${ }^{2,3,4}$ Wei-Zhen Wang, ${ }^{1}$ Xiao-Man Zhu, ${ }^{1}$ Julie A. Saugstad, ${ }^{1}$ Margaret P. Price, ${ }^{4}$ \\ Roger P. Simon, ${ }^{1,5}$ and Zhi-Gang Xiong ${ }^{1}$ \\ ${ }^{1}$ Robert S. Dow Neurobiology Laboratories, Legacy Research, Portland, Oregon 97232, ${ }^{2}$ Department of Psychiatry, University of Iowa, Iowa City, Iowa \\ 52242, ${ }^{3}$ Department of Veterans Affairs Medical Center, Iowa City, Iowa 52242, ${ }^{4}$ Department of Internal Medicine and Howard Hughes Medical Institute, \\ University of Iowa, Iowa City, Iowa 52242, and 5Department of Neurology, Physiology and Pharmacology, Oregon Health and Science University, Portland, \\ Oregon 97239
}

Acid-sensing ion channels (ASICs), a novel class of ligand-gated cation channels activated by protons, are highly expressed in peripheral sensory and central neurons. Activation of ASICs may play an important role in physiological processes such as nociception, mechanosensation, and learning-memory, and in the pathology of neurological conditions such as brain ischemia. Modulation of the activities of ASICs is expected to have a significant influence on the roles that these channels can play in both physiological and/or pathological processes. Here we show that the divalent cation $\mathrm{Zn}^{2+}$, an endogenous trace element, dose-dependently inhibits ASIC currents in cultured mouse cortical neurons at nanomolar concentrations. With ASICs expressed in Chinese hamster ovary cells, $\mathrm{Zn}^{2+}$ inhibits currents mediated by homomeric ASIC1a and heteromeric ASIC1a-ASIC2a channels, without affecting currents mediated by homomeric ASIC1 $\beta$, ASIC2a, or ASIC3. Consistent with ASIC1a-specific modulation, high-affinity $\mathrm{Zn}^{2+}$ inhibition is absent in neurons from ASIC1a knock-out mice. Current-clamp recordings and $\mathrm{Ca}^{2+}$-imaging experiments demonstrated that $\mathrm{Zn}^{2+}$ inhibits acid-induced membrane depolarization and the increase of intracellular $\mathrm{Ca}^{2+}$. Mutation of lysine-133 in the extracellular domain of the ASIC1a subunit abolishes the high-affinity $\mathrm{Zn}^{2+}$ inhibition. Our studies suggest that $\mathrm{Zn}^{2+}$ may play an important role in a negative feedback system for preventing overexcitation of neurons during normal synaptic transmission and ASICla-mediated excitotoxicity in pathological conditions.

Key words: acid-sensing ion channels; ASICs; zinc inhibition; excitability; patch clamp; neuron

\section{Introduction}

Decrease of extracellular $\mathrm{pH}\left(\mathrm{pH}_{\mathrm{o}}\right)$ activates acid-sensing ion channels (ASICs) in both peripheral sensory and central neurons (Waldmann et al., 1997a; Krishtal, 2003). ASICs belong to the amiloride-sensitive epithelial $\mathrm{Na}^{+}$channel-degenerin superfamily of ion channels (Corey and Garcia-Anoveros, 1996; Waldmann et al., 1997a; Benos and Stanton, 1999). So far, four genes encoding six ASIC subunits have been cloned. ASIC1a is expressed in both sensory and central neurons (Waldmann et al., 1997a), whereas its splice variant ASIC1 $\beta$ is expressed only in sensory neurons (Chen et al., 1998). Both ASIC1a and ASIC1 $\beta$ respond to low $\mathrm{pH}_{\mathrm{o}}$ by mediating a transient current with a $\mathrm{pH}_{0.5}$ at $\sim 6.0$. In addition to being $\mathrm{Na}^{+}$permeable, homomeric ASIC1a channels are also permeable to $\mathrm{Ca}^{2+}$ (Waldmann et al.,

Received July 14, 2004; revised Aug. 23, 2004; accepted Aug. 24, 2004.

This work was supported by National Institutes of Health Grants R01NS42926, NS047506 (Z.-G.X.), and R21NS42799 (R.P.S.), American Heart Association Grants 023028N (Z.-G.X.), 0225540Z, and $0465338 Z$ (X.-P.C.), Legacy Research Advisory Committee grant, Veterans Affairs Research Career Development Award (J.A.W.), and the Howard Hughes Medical Institute Biomedical Research Program (J.A.W. and M.P.P.). We thank Natasha Close and Suzanne Zeitouni for technical support, R. Waldmann and M. Lazdunski (Institut de Pharmacologie Moleculaire et Cellulaire, (entre National de la Recherche Scientifique, Valbonne, France) for ASIC clones, and E. W. McCleskey (Vollum Institute, Portland, OR) for CHO cells.

Correspondence should be addressed to Dr. Zhi-Gang Xiong, Robert S. Dow Neurobiology Laboratories, Legacy Research, 1225 Northeast Second Avenue, Portland, OR 97232. E-mail: zxiong@downeurobiology.org. DOI:10.1523/JNEUROSCI.2844-04.2004

Copyright $\odot 2004$ Society for Neuroscience $\quad$ 0270-6474/04/248678-12\$15.00/0 1997a; Chu et al., 2002; Yermolaieva et al., 2004), whereas homomeric ASIC1 $\beta$ (or ASIC1b) has no $\mathrm{Ca}^{2+}$ permeability (Chen et al., 1998; Bassler et al., 2001). ASIC2a is also expressed in peripheral sensory and central neurons (Price et al., 1996; Waldmann et al., 1996; Garcia-Anoveros et al., 1997). Homomeric ASIC2a has a low sensitivity to acid with a $\mathrm{pH}_{0.5}$ of $\sim 4.4$ (Price et al., 1996; Waldmann et al., 1996; Lingueglia et al., 1997). ASIC2b, a splice variant of ASIC2a, does not form functional homomeric channels (Lingueglia et al., 1997; Sutherland et al., 2001). ASIC3 is expressed predominantly in nociceptive sensory neurons (Waldmann et al., 1997b; Sutherland et al., 2001). Homomeric ASIC3 responds to $\mathrm{pH}$ drops biphasically, with a fast desensitizing current and a late sustained component (Waldmann et al., 1997b; De Weille et al., 1998). ASIC4 is highly expressed in pituitary gland (Akopian et al., 2000; Grunder et al., 2000; Lilley et al., 2004). Similar to ASIC2b, ASIC4 does not form functional homomeric channels.

In sensory neurons, ASICs are implicated in nociception (Krishtal and Pidoplichko, 1981; Bevan and Yeats, 1991; Benson et al., 1999; McCleskey and Gold, 1999; Yiangou et al., 2001; Chen et al., 2002; Ugawa et al., 2002; Krishtal, 2003; Sluka et al., 2003; Voilley, 2004), mechanosensation (Corey and Garcia-Anoveros, 1996; Price et al., 2000, 2001; Garcia-Anoveros et al., 2001), and taste transduction (Lindemann, 1996; Lin et al., 2002; Ugawa, 2003; Ugawa et al., 2003). In central neurons, ASICs are involved 
in synaptic plasticity, learning-memory (Wemmie et al., 2002), and fear conditioning (Wemmie et al., 2003, 2004), and in the pathology of neurological conditions such as seizures and brain ischemia (Biagini et al., 2001; Johnson et al., 2001). Because of its $\mathrm{Ca}^{2+}$ permeability, ASICla is involved in acidosis-mediated cell death and ischemic brain injury (Zhu et al., 2001; Xiong et al., 2004; Yermolaieva et al., 2004). ASIC2a is involved in the maintenance of retinal integrity (Ettaiche et al., 2004).

Recent studies have demonstrated that the activities of ASICs can be modulated by various endogenous signaling molecules; for example, ASIC currents are potentiated by neurochemical components associated with tissue inflammation (Askwith et al., 2000; Catarsi et al., 2001; Mamet et al., 2002; Deval et al., 2003) and ischemia (Immke and McCleskey, 2001; Allen and Attwell, 2002). So far, the reported modulations by endogenous molecules almost exclusively enhance the activation of ASICs. Here we demonstrate that $\mathrm{Zn}^{2+}$, an endogenous trace element released during neuronal activity (Assaf and Chung, 1984; Howell et al., 1984), is a potent negative modulator of ASICs.

A preliminary report of this work has been published previously (Chu et al., 2003a).

\section{Materials and Methods}

Primary cortical neuronal cultures. Primary cultures of mouse cortical neurons were prepared according to previously described techniques (Chu et al., 2003b). The use of mice for neuronal cultures was reviewed and approved by the Institutional Animal Care and Use Committee of Legacy Clinical Research and Technology Center. Briefly, time-pregnant (embryonic day 16) Swiss mice and postnatal day 1 (P1) C57BL/6, ASIC1, and ASIC2 knock-out mice were anesthetized with halothane followed by cervical dislocation. Brains of fetuses or P1 mice were removed rapidly and placed in $\mathrm{Ca}^{2+}$ - and $\mathrm{Mg}^{2+}$-free cold PBS. Cerebral cortices were dissected and incubated with $0.05 \%$ trypsin-EDTA for 10 $\min$ at $37^{\circ} \mathrm{C}$, followed by trituration with fire-polished glass pipettes, and plated in poly-L-ornithine-coated $35 \times 35 \mathrm{~mm}$ culture dishes at a density of $1 \times 10^{6}$ cells per dish. Neurons were cultured with Neurobasal medium supplemented with $\mathrm{B} 27$ and maintained at $37^{\circ} \mathrm{C}$ in a humidified $5 \% \mathrm{CO}_{2}$ atmosphere incubator. Cultures were fed twice a week and used for electrophysiological recording 12-14 d after plating.

Acute isolation of mouse cortical neurons. Mouse cortical neurons were acutely isolated according to our previously described technique (Xiong et al., 1999). Briefly, Swiss mice of 3-4 weeks were anesthetized with halothane and decapitated using a guillotine. The whole brain was removed and placed in cold extracellular solution (ECF) and subsequently sectioned at $400 \mu \mathrm{m}$ with a microtome (Leica VT 1000). The slices were then incubated in ECF containing $0.3-0.5 \mathrm{mg} / \mathrm{ml}$ papain (from papaya latex; Sigma, St. Louis, MO) at room temperature for $30 \mathrm{~min}$. All solutions were bubbled with $100 \% \mathrm{O}_{2}$. After the enzyme digestion, slices were washed three times and incubated in enzyme-free ECF for at least $30 \mathrm{~min}$ before dissociation. For the isolation of cortical neurons, one slice each time was transferred into a $35 \mathrm{~mm}$ culture dish containing $2 \mathrm{ml}$ of ECF, and the dish was placed on the stage of an inverted phase-contrast microscope. The cortical regions of the slices were cut out, and single cells were mechanically dissociated using two fire-polished glass pipettes or fine forceps. Electrophysiological recording of the isolated neurons began $\sim 15$ min after the mechanical dissociation.

Electrophysiology. Whole-cell patch-clamp recordings were performed as described previously (Chu et al., 2003b). Patch electrodes, with resistances between 3 and $5 \mathrm{M} \Omega$ when filled with intracellular solution, were constructed from thin-walled borosilicate glass (1.5 mm diameter; WPI, Sarasota, FL) on a two-stage puller (PP83, Narishige, Tokyo, Japan). Whole-cell currents or membrane potentials were recorded using Axopatch 1-D amplifiers (Axon Instruments, Foster City, CA). Data were filtered at $2 \mathrm{kHz}$ and digitized at $5 \mathrm{~Hz}$ using Digidata 1320 DAC units (Axon Instruments). The on-line acquisition was done using pCLAMP software (version 8, Axon Instruments).

In general, ASIC channels were activated by $\mathrm{pH}$ reduction every $2 \mathrm{~min}$ to avoid current desensitization. During each experiment, a voltage step of $-10 \mathrm{mV}$ from the holding potential was applied periodically to monitor the cell capacitance and access resistance. Recordings in which the access resistance or the capacitances changed by $>10 \%$ during the experiment were not included in data analysis (Xiong et al., 1998).

Solutions and chemicals. Standard extracellular solutions (ECF) contained (in mM): $140 \mathrm{NaCl}, 5.4 \mathrm{KCl}, 2.0 \mathrm{CaCl}_{2}, 1.0 \mathrm{MgCl}_{2}, 20$ HEPES, 10 glucose, $\mathrm{pH} 7.4$ (320-330 mOsm). For solutions with $\mathrm{pH} \leq 6.0$, MES was used instead of HEPES for more reliable pH buffering (Chu et al., 2002). For voltage-clamp recordings, the pipette solution contained (in $\mathrm{mM}$ ): $140 \mathrm{CsF}, 10$ HEPES, 11 EGTA, 2 TEA, $1 \mathrm{CaCl}_{2}, 2 \mathrm{MgCl}_{2}$, and $4 \mathrm{~K}_{2} \mathrm{ATP}$, pH 7.3 (300 mOsm). For current-clamp recording, CsF in the pipette solution was replaced with KF. $N, N, N^{\prime}, N^{\prime}$-tetrakis-(2-pyridylmethyl)ethylenediamine (TPEN), EDTA, $\mathrm{Zn}^{2+}$-EDTA, Ca ${ }^{2+}$-EDTA, $\mathrm{N}-(2-$ acetamido)iminodiacetic acid (ADA), diethylenetriaminepentaacetic acid (DTPA), $N$-tris(hydroxymethyl)methylglycine (tricine), and $\mathrm{ZnCl}_{2}$ were purchased from Sigma (St. Louis, MO).

A multibarrel perfusion system (SF-77, Warner Instruments, Hamden, CT) was used to achieve a rapid exchange of extracellular solutions.

Buffered $\mathrm{Zn}^{2+}$ solutions. For construction of $\mathrm{Zn}^{2+}$ dose-inhibition curves in the nanomolar concentration range, heavy metal chelators with different $\mathrm{Zn}^{2+}$ binding affinities were used according to a previously described method (Amar et al., 2001). For buffering free $\mathrm{Zn}^{2+}$ in the rage of $3 \mathrm{nM}$ to $1 \mu \mathrm{M}, 10 \mathrm{~mm}$ tricine, a $\mathrm{Zn}^{2+}$ chelator with moderate affinity $\left(K_{\mathrm{D}}=10^{-5} \mathrm{M}\right)$ was used, and the free $\mathrm{Zn}^{2+}$ was calculated using the following equation: $\left[\mathrm{Zn}^{2+}\right]_{\text {free }}=\left[\mathrm{Zn}^{2+}\right]_{\text {total }} / 200$. For buffering free $\mathrm{Zn}^{2+}$ in the range of $0.05-3 \mathrm{nM}, 1 \mathrm{~mm} \mathrm{ADA}$, a $\mathrm{Zn}^{2+}$ chelator with high affinity $\left(K_{\mathrm{D}}=10^{-7.3} \mathrm{M}\right)$ was used, and the free $\mathrm{Zn}^{2+}$ was calculated using the following equation: $\left[\mathrm{Zn}^{2+}\right]_{\text {free }}=\left[\mathrm{Zn}^{2+}\right]_{\text {total }} / 17,000$ (Amar et al., 2001). For all $\mathrm{Zn}^{2+}$-inhibition dose-response curves, a $\mathrm{Zn}^{2+}$-free reference solution was made by adding $10 \mu \mathrm{M}$ TPEN, a strong $\mathrm{Zn}^{2+}$ chelator $\left(K_{\mathrm{D}}=10^{-15.6} \mathrm{M}\right)$, or $10 \mathrm{~mm}$ tricine to the solution without added $\mathrm{Zn}^{2+}$.

Transfection of Chinese hamster ovary cells. Chinese hamster ovary $(\mathrm{CHO})$ cells were cultured in F12 medium (American Type Culture Collection, Manassas, VA) supplemented with $10 \%$ fetal bovine serum. At $\sim 50 \%$ confluence, cells were cotransfected with DNA for various ASICs and for green fluorescent protein (GFP) in the pcDNA3 vector (Invitrogen, San Diego, CA), using Fugene 6 transfection reagent (Roche Diagnostics, Indianapolis, IN). For each $35 \times 35 \mathrm{~mm}$ culture dish, $0.75 \mu \mathrm{g}$ of cDNA for individual ASIC and $0.25 \mu \mathrm{g}$ of DNA for GFP were used. For coexpression of ASIC1a plus ASIC2a, equal amounts of each cDNA $(0.75$ $\mu \mathrm{g})$ were used. All recordings were made $48-72 \mathrm{hr}$ after plating. GFPpositive cells were viewed under a fluorescent microscope for patchclamp recording.

Site-directed mutagenesis. ASICla point mutations were made using the Quick-Change Site-Directed Mutagenesis System (Stratagene, La Jolla, CA) in accordance with the manufacturer's protocol. The primers were obtained from Sigma-Genosys (The Woodlands, TX). Mutations were confirmed by restriction enzyme digest and DNA sequence analysis. In all cases, the entire ASIC1a cDNA was sequenced to determine whether any nonspecific mutations were introduced.

$\mathrm{Ca}^{2+}$ imaging. Fura-2 fluorescent $\mathrm{Ca}^{2+}$ imaging was performed as described previously (Xiong et al., 2000, 2001). Cortical neurons grown on $25 \times 25 \mathrm{~mm}$ glass coverslips were washed three times with ECF and incubated with $5 \mu \mathrm{M}$ fura-2-acetoxymethyl ester for $\sim 40 \mathrm{~min}$ at room temperature. Neurons were then washed three times and incubated in normal ECF for $30 \mathrm{~min}$. Coverslips with fura-2-loaded neurons were transferred to a perfusion chamber on an inverted microscope (Nikon TE300). Cells were illuminated using a xenon lamp (75 W) and observed with a $40 \times$ UV fluor oil-immersion objective lens. Video images were obtained using a cooled CCD camera (Sensys KAF 1401, Photometrics, Tucson, AZ). Digitized images were acquired, stored, and analyzed in a PC controlled by Axon Imaging Workbench software (AIW2.1, Axon Instruments). The shutter and filter wheel (Lambda 10-2, Sutter Instrument, Novato, CA) were also controlled by AIW to allow timed illumination of cells at either 340 or $380 \mathrm{~nm}$ excitation wavelengths. Fura-2 fluorescence was detected at an emission wavelength of $510 \mathrm{~nm}$. Ratio images of 340/380 were analyzed by averaging pixel ratio values in cir- 
cumscribed regions of cells in the field of view. The values were exported from AIW to SigmaPlot for further analysis and plotting.

Data analysis. All data are expressed as mean \pm SEM. Student's $t$ test was used to examine the statistical significance of the difference between groups of data. The criterion of significance was set at $p<0.05$.

\section{Results}

\section{Chelation of contaminating $\mathrm{Zn}^{2+}$ potentiates ASIC currents} in cultured mouse cortical neurons

In all cultured mouse cortical neurons voltage clamped at -60 $\mathrm{mV}$, a rapid reduction of $\mathrm{pH}_{\mathrm{o}}$ from 7.4 to 6.5 evoked a large transient inward current, as described previously (Varming, 1999; Xiong et al., 2004). The peak amplitude of acid-activated current increases with larger decreases in $\mathrm{pH}$, and a maximal current was activated by a $\mathrm{pH}$ decrease to 4.0. The amplitude of acid-activated current decreases with more depolarized membrane potential, with a reversal potential close to $\mathrm{Na}^{+}$equilibrium potential (approximately $+60 \mathrm{mV}$ ). The current is sensitive to blockade by amiloride with an $\mathrm{IC}_{50}$ value of $\sim 15 \mu \mathrm{M}$ (Xiong et al., 2004). Previous studies also indicated that ASIC current in cortical neurons is likely carried by a mixture of homomeric ASIC1a, ASIC2a, and heteromeric ASIC1a-ASIC2a channels (Xiong et al., 2004).

The potential effect of $\mathrm{Zn}^{2+}$ on ASIC current in cortical neurons was initially studied by adding $\mathrm{Zn}^{2+}$ directly into the extracellular solutions. Similar to a previous study performed in rat hippocampal neurons (Baron et al., 2002), bath application of high micromolar concentrations of $\mathrm{Zn}^{2+}$ (100-300 $\left.\mu \mathrm{M}\right)$ potentiated ASIC current by $\sim 50 \%$ in 38 of 64 neurons (data not shown). This finding indicates that ASICs in more than half of the cortical neurons contain the ASIC2a subunit. In the majority of cortical neurons, however, addition of $\mathrm{Zn}^{2+}$ below $30 \mu \mathrm{M}$ had no detectable effect ( $n=12$; data not shown), indicating the lack of high-affinity $\mathrm{Zn}^{2+}$ modulation of ASICs. Previous studies, however, have reported that most physiological solutions contain contaminating concentrations of $\mathrm{Zn}^{2+}$ in the range of $20-50 \mathrm{nM}$ (Paoletti et al., 1997; Amar et al., 2001) or higher (Zheng et al., 1998; Wilkins and Smart, 2002). The lack of effect by low micromolar $\mathrm{Zn}^{2+}$ may also suggest that a high-affinity $\mathrm{Zn}^{2+}$ binding site or sites, if any, have already been saturated by contaminating $\mathrm{Zn}^{2+}$ in the extracellular solutions. To test this hypothesis, we examined the effect of TPEN, a high-affinity $\mathrm{Zn}^{2+}$ chelator (Arslan et al., 1985; Paoletti et al., 1997), on ASIC currents. After recordings of stable ASIC currents activated by $\mathrm{pH}$ reduction from 7.4 to 6.5, various concentrations of TPEN were added to the bath solutions. As shown in Figure 1, addition of TPEN above $0.3 \mu \mathrm{M}$ dramatically potentiated ASIC currents in a dosedependent and reversible manner (Fig. $1 A$ ). A maximal potentiation was achieved by $10 \mu \mathrm{M}$ TPEN with an approximately twofold increase in the amplitude of ASIC currents (control: $-1290.72 \pm 127.99 \mathrm{pA}$; TPEN: $-2451.33 \pm 172.15 \mathrm{pA} ; n=64$; $p<0.001)$. A detailed dose-response analysis revealed an $\mathrm{EC}_{50}$ value of $2.3 \pm 0.36 \mu \mathrm{M}$ and a Hill coefficient of $1.1 \pm 0.01$ for TPEN potentiation of the current $(n=8)$ (Fig. $1 B$ ). In most cells, the maximal potentiation by TPEN can be reached within 2-4 min after perfusion of TPEN, and the effect is fully reversible after a complete washout of TPEN. Adding TPEN $(0.3-30 \mu \mathrm{M})$ alone to $\mathrm{pH} 7.4$ solution does not activate any current on its own, and coapplication of TPEN with $\mathrm{pH} 6.5$ for $10 \mathrm{sec}$ is not sufficient to induce notable potentiation of the ASIC currents (data not shown).
A

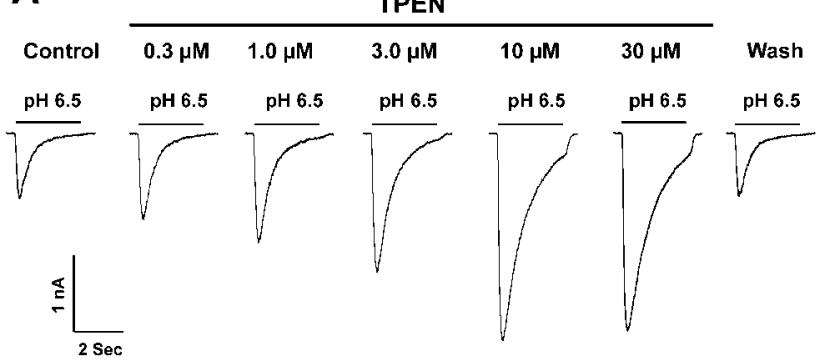

B
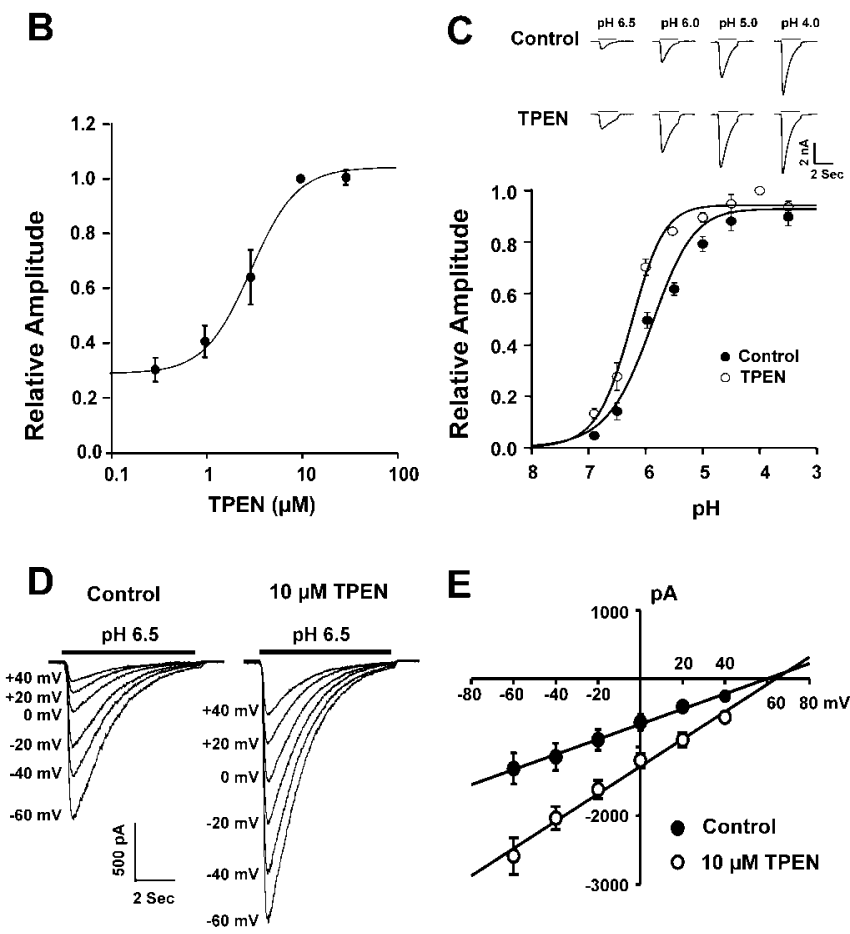

Figure 1. Chelation of contaminating $\mathrm{Zn}^{2+}$ by TPEN potentiates the ASIC current in cultured mouse cortical neurons. $A$, Representative traces showing concentration-dependent potentiation of the ASIC current in cultured mouse cortical neurons by bath application of the highaffinity $\mathrm{Zn}^{2+}$ chelating agent TPEN. $B$, Dose-response curve for TPEN potentiation with an average $\mathrm{EC}_{50}$ value of $2.3 \pm 0.36 \mu \mathrm{m}$ and a Hill coefficient of $1.1 \pm 0.01 ; n=8$. C, TPEN potentiates the ASIC current by inducing a leftward shift of $\mathrm{pH}$ dose-response curve for the ASICs. In the absence of TPEN, the $\mathrm{pH}_{0.5}$ is $5.92 \pm 0.07$; with $10 \mu \mathrm{M}$ TPEN the $\mathrm{pH}_{0.5}$ is $6.26 \pm$ $0.06 ; n=5 ; p<0.05$. D, Representative traces showing the ASIC current activated at different holding potentials ranging from -60 to $+40 \mathrm{mV}$ in the absence and presence of $10 \mu \mathrm{m}$ TPEN. Currents were activated by $\mathrm{pH}$ reduction from 7.4 to 6.5 . F, Current-voltage relationship (I-V curve) before $(O)$ and after $10 \mu \mathrm{m} \operatorname{TPEN}(\bigcirc) ; n=5$. Both curves were fit by a straight line with reversal potential at approximately $+60 \mathrm{mV}$.

\section{Potentiation of ASIC current by $\mathrm{Zn}^{2+}$ chelation is pH dependent}

We next determined whether potentiation of the ASIC current by $\mathrm{Zn}^{2+}$ chelation depends on the level of $\mathrm{pH}_{\mathrm{o}} \cdot \mathrm{pH}$ dose-response curves were generated before and after $10 \mu \mathrm{M}$ TPEN. As shown in Figure $1 C$, application of TPEN induced a relatively larger potentiation of the ASIC current at higher $\mathrm{pH}$ (e.g., 6.5) than at lower $\mathrm{pH}$ (e.g., 5.0), resulting in a leftward shift of the $\mathrm{pH}$ dose-response curve $\left(\mathrm{pH}_{0.5}\right.$ before TPEN: $5.92 \pm 0.07$; after $10 \mu \mathrm{M}$ TPEN: $6.26 \pm 0.06 ; n=5 ; p<0.05)$. Hill coefficient was not significantly affected by TPEN (before TPEN: $0.93 \pm 0.01$; after TPEN: $0.94 \pm 0.01 ; n=5 ; p>0.05)$. The maximal current recorded at $\mathrm{pH} 4.0$ was not significantly potentiated by TPEN (Fig. 1C, top). This finding suggests that potentiation of ASIC 
currents by TPEN is caused to a large extent by an increase in the apparent affinity of ASICs to $\mathrm{H}^{+}$.

We then examined whether TPEN potentiation of ASIC currents depends on the membrane potential. Currents were activated by $\mathrm{pH}$ reduction from 7.4 to 6.5 with membrane potential held at different values. Addition of $10 \mu \mathrm{M}$ TPEN potentiated the ASIC current to a similar extent at all potentials ranging from -60 to $+40 \mathrm{mV}$, indicating the lack of a voltage-dependent effect (Fig. $1 D, E$ ). In addition, the reversal potential of ASIC currents remained unchanged in the presence of TPEN, suggesting that TPEN potentiates ASIC currents without altering the $\mathrm{Na}^{+}$selectivity of the channels.

Extracellular sites are involved in the potentiation of ASIC current by $\mathrm{Zn}^{2+}$ chelation

TPEN was selected for its powerful $\mathrm{Zn}^{2+}$ chelating properties but poor $\mathrm{Ca}^{2+}$ binding affinity (Arslan et al., 1985; Paoletti et al., 1997); however, it is known that TPEN permeates readily biological membranes. It is therefore not clear whether TPEN potentiates the ASIC current by chelating extracellular $\mathrm{Zn}^{2+}$ or whether it enters the cell and potentiates ASIC currents by chelating intracellular $\mathrm{Zn}^{2+}$. To answer this question, we tested the effects of several membrane-impermeant heavy-metal chelators, including EDTA, DTPA, and ADA. Similar to TPEN, all three compounds significantly potentiated the ASIC current (Fig. $2 A, B)(n=8 ; p<$ 0.01 ), suggesting that the potentiation of ASIC current is caused by chelation of $\mathrm{Zn}^{2+}$ on the extracellular side of the membrane. To provide additional evidence, we also included $100 \mu \mathrm{M}$ EDTA in the pipette solution to chelate intracellular $\mathrm{Zn}^{2+}$ before testing the effect of TPEN in the bath solution. After formation of wholecell configuration, up to 20 min was allowed for EDTA to diffuse into neurons to chelate intracellular free $\mathrm{Zn}^{2+}$. Then $10 \mu \mathrm{M}$ TPEN was added to the bath solution to determine whether it could still potentiate the ASIC current. As shown in Figure 2, C and $D$, chelation of intracellular $\mathrm{Zn}^{2+}$ with EDTA did not attenuate the potentiation of ASIC current by bath perfusion of TPEN, further indicating an involvement of an extracellular site or sites in $\mathrm{Zn}^{2+}$ inhibition of the ASIC current.

To clearly demonstrate whether EDTA potentiates the ASIC current through its $\mathrm{Zn}^{2+}$ or $\mathrm{Ca}^{2+}$ chelating activity, we tested the effects of $\mathrm{Ca}^{2+}$-EDTA, a heavy-metal chelator that does not bind $\mathrm{Ca}^{2+}$, and $\mathrm{Zn}^{2+}$-EDTA, a chelator that does not bind $\mathrm{Zn}^{2+}$. As shown in Figure 2, $E$ and $F$, bath perfusion of $\mathrm{Ca}^{2+}$-EDTA (30 $\mu \mathrm{M})$ significantly potentiated the ASIC current; however, perfusion of $\mathrm{Zn}^{2+}$-EDTA had no effect on the current, further indicating that potentiation of the ASIC current by EDTA is caused by its $\mathrm{Zn}^{2+}$ chelating activity. Consistent with $\mathrm{Zn}^{2+}$ chelation as the mechanism underlying the potentiation of ASIC current by

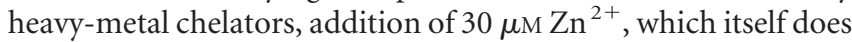
not affect the current in the majority of cortical neurons, blocked the potentiation of ASIC current by TPEN (Fig. $2 G, H)(n=5)$.

A moderate decrease (e.g., $\sim 0.3 \mathrm{~mm}$ ) in extracellular $\mathrm{Ca}^{2+}$ is known to potentiate ASIC3 current in cardiac sensory neurons (Immke and McCleskey, 2001). This is unlikely to be the mechanism underlying EDTA-induced potentiation of the ASIC current observed here, because EDTA has a poor $\mathrm{Ca}^{2+}$ chelating affinity. With a total of $2 \mathrm{mM} \mathrm{Ca}^{2+}$ and $1 \mathrm{mM} \mathrm{Mg}^{2+}$ present in the extracellular solutions, addition of $30 \mu \mathrm{M}$ EDTA is expected to reduce unbound $\mathrm{Ca}^{2+}$ and $\mathrm{Mg}^{2+}$ to 1.97 and $0.99 \mathrm{~mm}$, respectively. This reduction of $\mathrm{Ca}^{2+}$ and $\mathrm{Mg}^{2+}$ is too small to induce a visible increase in ASIC currents in cortical neurons (data not shown).
A
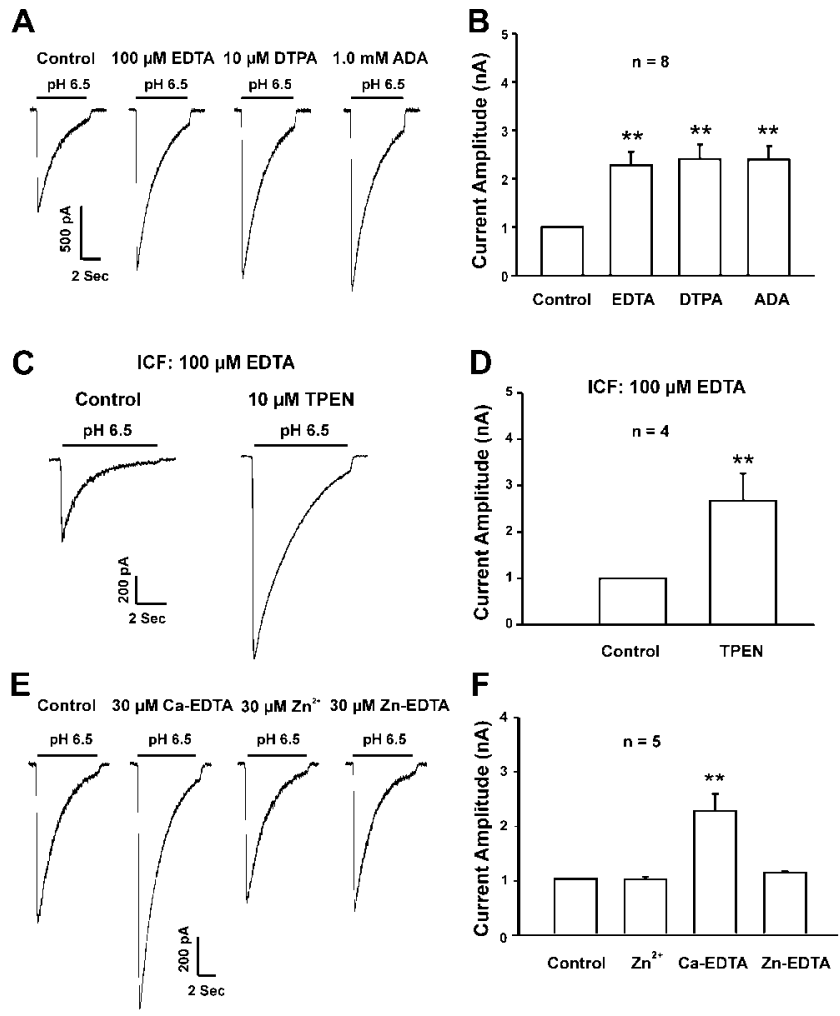

G
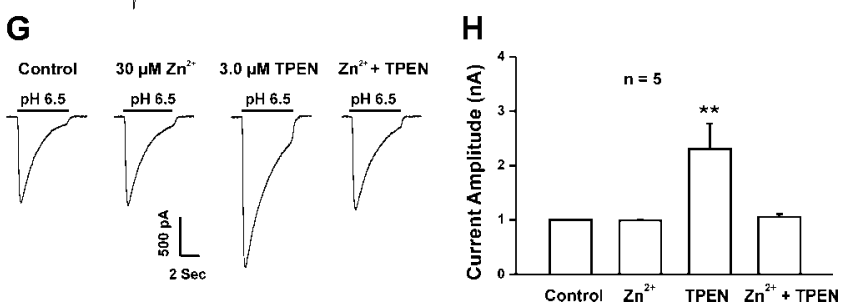

Figure 2. Chelation of the extracellular $\mathrm{Zn}^{2+}$ is responsible for potentiation of the ASIC current. $A, B$, Representative current traces and summary data showing potentiation of the ASIC current by the membrane-impermeable $\mathrm{Zn}^{2+}$ cheating agents EDTA, DTPA, and ADA. All three agents induced more than a twofold increase in the amplitude of ASIC current; $n=8 . C, D$, Chelation of intracellular free $\mathrm{Zn}^{2+}$ by inclusion of $100 \mu \mathrm{m}$ EDTA in the pipette solution does not affect the potentiation of ASIC current by bath application of TPEN $(10 \mu \mathrm{M}) ; n=4$. E, F, Representative current traces and summary data showing potentiation of ASIC current by $\mathrm{Ca}^{2+}$-EDTA but not by $\mathrm{Zn}^{2+}-$ EDTA; $n=5$. G, H, TPEN potentiation of the ASIC current is reversed by the presence of $30 \mu \mathrm{m} \mathrm{Zn}{ }^{2+}$, which by itself has no effect on the current in the majority of cortical neurons; $n=5 ;{ }^{* *} p<0.01$.

\section{Chelation of $\mathrm{Zn}^{2+}$ potentiates ASIC current in neurons containing either homomeric ASIC1a or heteromeric ASIC1a-ASIC2a channels}

ASIC1a and ASIC2a are the major ASIC subunits in neurons of mammalian brain. ASIC currents in these neurons are believed to be mediated by a combination of homomeric ASIC1a, ASIC2a, and heteromeric ASIC1a-ASIC2a channels (Baron et al., 2002; Askwith et al., 2004; Xiong et al., 2004). Because homomeric ASIC2a has a low $\mathrm{H}^{+}$sensitivity and cannot be activated with a $\mathrm{pH}$ drop from 7.4 to above 5.5, it is expected that currents activated by a $\mathrm{pH}$ decrease from 7.4 to 6.5 in cortical neurons are mediated by either homomeric ASIC1a or heteromeric ASIC1aASIC2a, or both. The next experiment was intended to determine which ASIC subunit(s) is involved in $\mathrm{Zn}^{2+}$ inhibition of the ASIC current in native neurons.

Because currents mediated by heteromeric ASIC1a-ASIC2a, but not homomeric ASICla channels, are potentiated by high 
concentrations of $\mathrm{Zn}^{2+}$ (Baron et al., 2001), we used $\mathrm{Zn}^{2+}$ potentiation as an indication of ASIC2a-containing channels in cortical neurons. In 59.4\% (38 of 64) of neurons recorded, addition

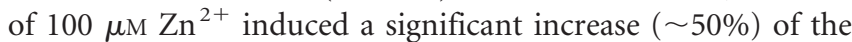
peak ASIC current activated at $\mathrm{pH} 6.5$ (from $-1513.13 \pm 152.24$ to $-2247.66 \pm 208.06 \mathrm{pA}$ ) (Fig. $3 A, B$ ). Because homomeric ASIC2a has a low acid sensitivity and is not expected to be activated at a $\mathrm{pH}$ of 6.5 , the current activated at 6.5 and potentiated

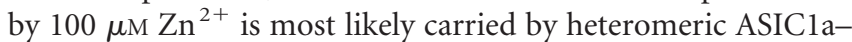
ASIC2a. In these neurons, $10 \mu \mathrm{M}$ TPEN enhanced the peak current from $-1513.13 \pm 152.24$ to $-2432.77 \pm 200.57 \mathrm{pA}$, an increase of $\sim 1.6$-fold (Fig. $3 A, B)(n=38 ; p<0.001)$. In the remaining neurons (26 of 64), addition of $100 \mu \mathrm{M} \mathrm{Zn^{2+ }}$ did not potentiate the ASIC current, as expected for homomeric ASIC1a (control: $-939.61 \pm 202.65 \mathrm{pA}$; with $100 \mu \mathrm{M} \mathrm{Zn^{2+ }}$ : $-859.00 \pm$ $194.83 \mathrm{pA} ; n=26 ; p>0.05)$. In these neurons, $10 \mu \mathrm{M}$ TPEN dramatically increased the ASIC current from $-939.61 \pm 202.65$ to $-2439.75 \pm 308.61 \mathrm{pA}$, an increase of nearly 2.6-fold (Fig. $3 C, D)(n=26 ; p<0.01)$. These findings indicate that, in native neurons, $\mathrm{Zn}^{2+}$ chelation potentiates ASIC currents mediated by both homomeric ASIC1a and heteromeric ASIC1a-ASIC2a channels; however, potentiation of the current mediated by homomeric ASICla channels is apparently greater.

Similar to cultured neurons, potentiation of the ASIC current by TPEN was also observed in acutely dissociated cortical neurons from adult mice ( $>4$ weeks). As shown in Figure 3, $E$ and $F$, $10 \mu \mathrm{M}$ TPEN increased the peak current from $-366.54 \pm 67.43$ to $-500.60 \pm 87.85 \mathrm{pA}$ in acutely dissociated cortical neurons $(n=$ $7 ; p<0.05)$.

\section{Dose-dependent inhibition of ASIC current in cortical neurons by buffered $\mathrm{Zn}^{2+}$}

Concentration of contaminating $\mathrm{Zn}^{2+}$ in most physiological solutions is estimated to be in the range of $20-50 \mathrm{nM}$ (Paoletti et al., 1997; Amar et al., 2001) or higher (Zheng et al., 1998; Wilkins and Smart, 2002). Potentiation of ASIC currents by $\mathrm{Zn}^{2+}$ chelating agents suggests that $\mathrm{Zn}^{2+}$ inhibits ASICs at nanomolar concentrations. To further test this hypothesis, we constructed a complete $\mathrm{Zn}^{2+}$ dose-inhibition curve with solutions containing buffered concentrations of free $\mathrm{Zn}^{2+}$ (see Materials and Methods). A solution with $10 \mu \mathrm{M}$ TPEN or $10 \mathrm{~mm}$ tricine with no added $\mathrm{Zn}^{2+}$ was used as the " $\mathrm{Zn}{ }^{2+}$-free" reference solution. Solutions with various concentrations of buffered $\mathrm{Zn}^{2+}$ were then perfused onto the cell to determine their effects on the ASIC current. As shown in Figure 3, $G$ and $H, \mathrm{Zn}^{2+}$ dose-dependently inhibits ASIC currents with an $\mathrm{IC}_{50}$ value of $14.2 \pm 0.36 \mathrm{~nm}$ and a Hill coefficient of $0.86 \pm$ $0.01(n=6)$. The inhibition of ASIC currents by $\mathrm{Zn}^{2+}$ is partial, with a maximal inhibition of $\sim 70 \%$ reached at $>30 \mathrm{~nm} \mathrm{Zn}^{2+}$. An additional increase in the $\mathrm{Zn}^{2+}$ concentration (up to $30 \mu \mathrm{M}$; data not shown) did not produce additional inhibition of the current.

\section{Effects of $\mathrm{Zn}^{2+}$ chelation on ASIC currents in neurons from ASIC1 and ASIC2 knock-out mice}

As mentioned above, ASIC1a and ASIC2a are the predominant ASIC subunits in CNS neurons, and the overall ASIC currents in cortical neurons are likely mediated by a combination of ASIC1a and/or ASIC2a subunits. To further determine the role of each subunit in high-affinity $\mathrm{Zn}^{2+}$ inhibition of the ASIC current in native neurons, we studied $\mathrm{Zn}^{2+}$ inhibition of ASIC currents in cortical neurons cultured from ASIC1 and ASIC2 knock-out mice (Price et al., 2000; Wemmie et al., 2002).

In all cortical neurons from ASIC1- $1-$ mice, no detectable ASIC current was activated by $\mathrm{pH}$ drops from 7.4 to $6.0(n=52)$
(Xiong et al., 2004), similar to a previous finding in hippocampal neurons (Wemmie et al., 2002). In 27 of 52 neurons, however, inward currents were activated by reductions of $\mathrm{pH}$ to $<5.5$. Detailed $\mathrm{pH}$ dose-response studies revealed a $\mathrm{pH}_{0.5}$ of $4.12 \pm$ 0.08 and a Hill coefficient of $0.99 \pm 0.03(n=3)$. Addition of $\mathrm{Zn}^{2+}(100-300 \mu \mathrm{M})$ significantly potentiated the current in these neurons ( $n=7$; data not shown). These findings suggest that currents activated in ASIC1-/- neurons are most likely mediated by homomeric ASIC2a channels. Perfusion of $10 \mu \mathrm{M}$ TPEN to these neurons, however, did not potentiate the ASIC current (Fig. $4 A, B)(n=7)$. In contrast to neurons from the ASIC1-/mice, all neurons from ASIC2-/- mice responded to $\mathrm{pH} 6.5$ with a transient inward current. Addition of TPEN significantly potentiated the ASIC current in these neurons (control: $-566.12 \pm 54.38 \mathrm{pA} ; 3 \mu \mathrm{M}$ TPEN: $-1216.96 \pm 83.54 \mathrm{pA} ; n=7)$ (Fig. 4C,D). A complete $\mathrm{Zn}^{2+}$ dose-inhibition curve was also constructed in neurons from ASIC2-/- mice, yielding an $\mathrm{IC}_{50}$ value of $4.95 \pm 0.58 \mathrm{nM}$ for $\mathrm{Zn}^{2+}$ inhibition of the current (Fig. $4 E, F)(n=6)$.

Similar to the ASIC current in cortical neurons cultured from Swiss mice, ASIC current in neurons from C57BL/6 mice, a wildtype (WT) control with the same genomic background as the ASIC knock-out mice, was also potentiated by TPEN (Fig. $4 G, H)$, indicating that genomic background has no influence on high-affinity $\mathrm{Zn}^{2+}$ inhibition of the ASIC current.

\section{High-affinity $\mathrm{Zn}^{2+}$ inhibition of ASIC currents in CHO cells} Our studies in native neurons suggest that the ASIC1a subunit is critical for high-affinity $\mathrm{Zn}^{2+}$ inhibition. To clearly identify the specific ASIC subunit(s) responsible for $\mathrm{Zn}^{2+}$ binding, we studied the effect of $\mathrm{Zn}^{2+}$ on ASIC currents mediated by different subunits of ASICs expressed in CHO cells. Similar to previous reports, homomeric ASIC1a and ASIC $1 \beta$ responded to moderate reductions of $\mathrm{pH}$ (e.g., to 6.5 or 6.0 ) with a transient inward current at $-60 \mathrm{mV}$ (Fig. 5A). A detailed pH dose-response study yielded a $\mathrm{pH}_{0.5}$ of $\sim 6.2$ for homomeric ASIC1a channels (Fig. $6 A$ ). Homomeric ASIC2a was not activated by $\mathrm{pH}$ drop to $>5.5$, but a large current was activated after $\mathrm{pH}$ drop to 4.5 (Fig. $5 \mathrm{~A}$ ). ASIC3 was activated by a moderate reduction of $\mathrm{pH}$ with a biphasic current (fast desensitizing current followed by a sustained component) (Fig. 5A). Consistent with findings in native neurons, bath perfusion of TPEN dramatically potentiated the current mediated by homomeric ASIC1a more than twofold $(n=5$; $p<0.01)$. No effect was observed on currents mediated by homomeric ASIC1 $\beta$, ASIC2a, or ASIC3 $(n=5-7)$ (Fig. $5 A, B$ ). Baron and colleagues (2001) demonstrated that $\mathrm{Zn}^{2+}$ potentiation of ASIC current mediated by ASIC2a-containing channels appears only between $\mathrm{pH} 6.9$ and 5.0, independent of the $\mathrm{pH}$ dependence of various subunit combinations. To exclude the possibility that the lack of TPEN potentiation of ASIC2a current is caused by the low $\mathrm{pH}$ value used, we also studied the effect of TPEN on ASIC2a current activated at a $\mathrm{pH}$ of 5.0 (Fig. 5C). Again, no potentiation by TPEN $(10 \mu \mathrm{M})$ was observed $(n=5)$. These data further suggest that the lack of TPEN potentiation of ASIC2a current is likely attributable to the lack of a high-affinity $\mathrm{Zn}^{2+}$ binding site on this subunit.

A detailed dose-response curve for TPEN potentiation of the homomeric ASIC1a current was then constructed, yielding an $\mathrm{EC}_{50}$ value of $1.4 \pm 0.02 \mu \mathrm{M}(n=5)$ (Fig. $\left.6 \mathrm{~B}\right)$. Similar to TPEN, the membrane-impermeant $\mathrm{Zn}^{2+}$ chelator $\mathrm{Ca}^{2+}$-EDTA and ADA both potentiated the ASIC1a current $(n=5-12)$ (Fig. $6 C$ ). In contrast, $\mathrm{Zn}^{2+}$-EDTA, which does not chelate $\mathrm{Zn}^{2+}$, had no effect $(n=5)$ (Fig. 6C). A $\mathrm{Zn}^{2+}$ dose-inhibition curve was also 
A

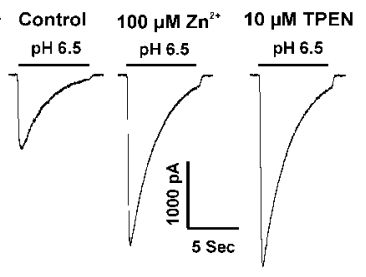

C

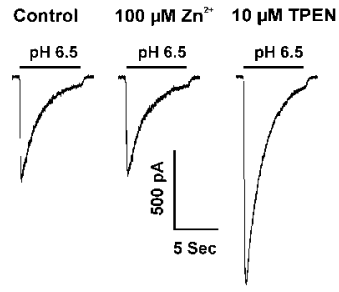

E

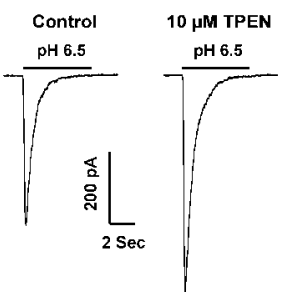

G

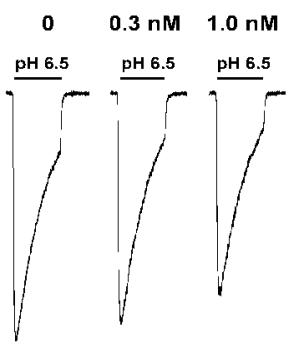

B

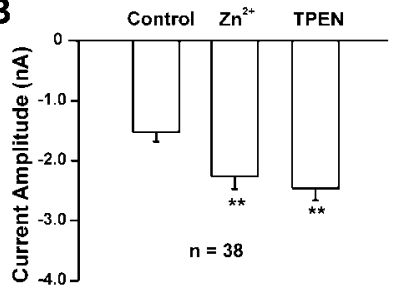

D

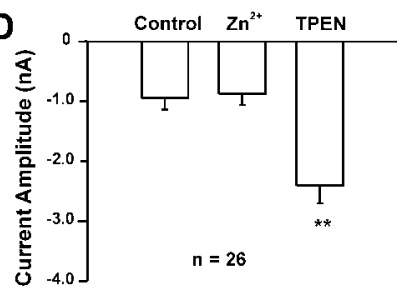

F

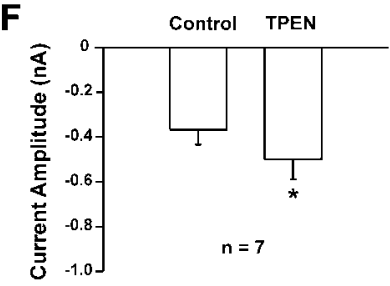

H

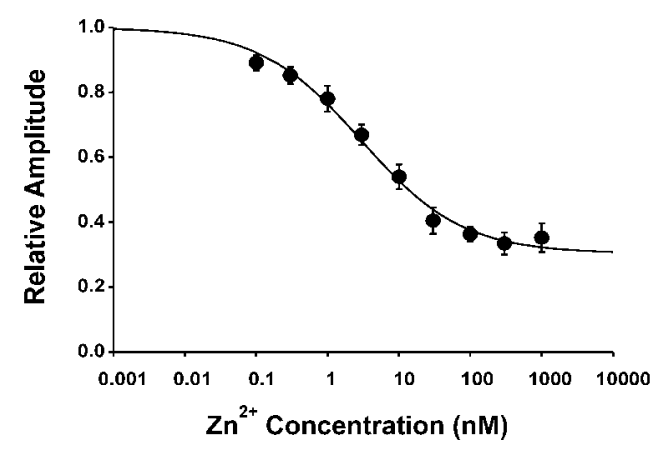

Figure 3. Evidence that $\mathrm{Zn}^{2+}$ chelation potentiates the currents mediated by either homomeric ASIC1a or heteromeric ASIC1a-ASIC2a channels in native neurons and dose-dependent inhibition of ASIC current in cortical neurons by buffered free $\mathrm{Zn}^{2+}$ at nanomolar concentrations. $A, B$, Representative traces and summary data showing TPEN potentiation of ASIC current that is likely carried by heteromeric ASIC1a-ASIC2a channels in cortical neurons. Currents in these neurons are activated by moderate $\mathrm{pH}$ decrease and potentiated by $100 \mu \mathrm{m} \mathrm{Zn}{ }^{2+}$, consistent with the presence of ASIC1a-ASIC2a channels. C, D, Representative traces and summary data showing TPEN potentiation of ASIC current that is likely carried by homomeric ASIC1a channels in cortical neurons. Currents in these neurons are activated by a moderate decrease of $\mathrm{pH}$ but are insensitive to $100 \mu \mathrm{m} \mathrm{Zn}{ }^{2+}$, consistent with the presence of homomeric ASIC1a channels. $E, F$, ASIC currents in acutely dissociated mature neurons are also potentiated by $\mathrm{Zn}^{2+}$ chelation. $G$, Representative traces demonstrating concentration-dependent inhibition of the ASIC current in cultured mouse cortical neurons by different concentrations of free $\mathrm{Zn}^{2+}$. ASIC currents were activated by $\mathrm{pH}$ reduction from 7.4 to 6.5 at a holding potential of $-60 \mathrm{mV}$. $\mathrm{H}$, Summary of $\mathrm{Zn}^{2+}$ dose-inhibition relationship from six neurons with an average $\mathrm{IC}_{50}$ value of $14.2 \pm 0.36 \mathrm{~nm}$ and a Hill coefficient of $0.86 \pm 0.01$. The inhibition of ASIC currents by $\mathrm{Zn}^{2+}$ is partial, with $\sim 30 \%$ residual current left at a concentration of $\mathrm{Zn}^{2+}>300 \mathrm{~nm}$. ${ }^{*} p<0.05$; ${ }^{* *} p<0.01$.
A
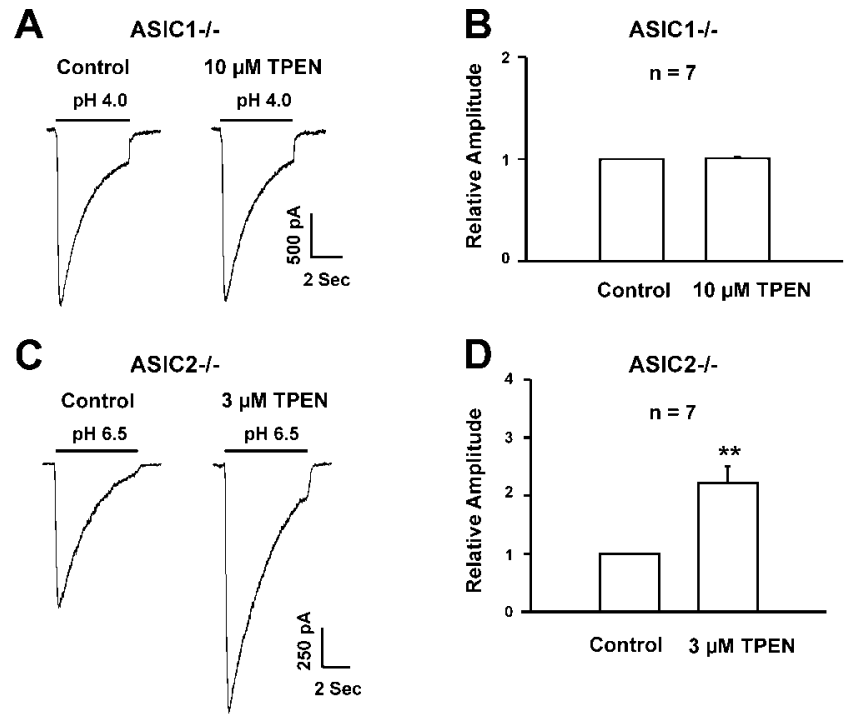

E
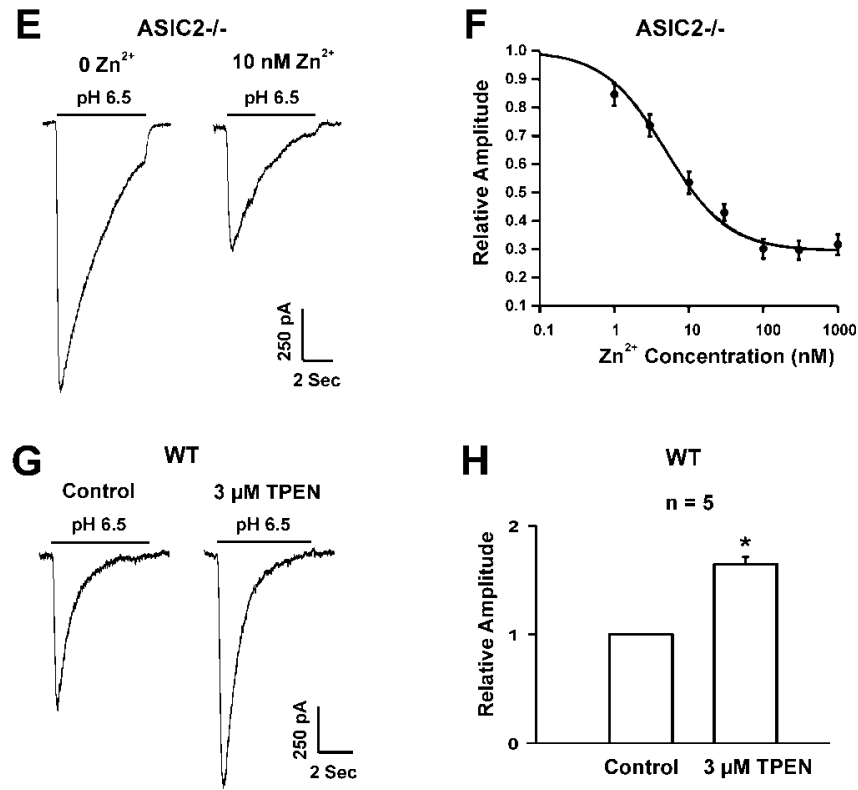

Figure 4. $\mathrm{Zn}^{2+}$ chelation potentiates the ASIC current in neurons from ASIC2 - / - mice but not in neurons from ASIC1 - I- mice. $A, B$, Representative traces and summary data showing the lack of potentiation of ASIC current by TPEN in neurons from ASIC $1-/-$ mice; $n=7$.C, $D$, Knock-out of the ASIC2 subunit does not affect TPEN potentiation of ASIC current in cortical neurons; $n=7 ;{ }^{* *} p<0.01$. E, $F$, ASIC currents in neurons from ASIC2 $-1-$ mice are inhibited by buffered $\mathrm{Zn}^{2+}$ with an average $\mathrm{IC}_{50}$ value of $4.95 \pm 0.58 \mathrm{~nm} ; n=6 . \mathrm{G}, \mathrm{H}, \mathrm{Zn}^{2+}$ chelation also potentiates the ASIC current in cortical neurons from C57BL/6 mice, a wild-type control for ASIC knock-out mice; $n=5 ;{ }^{*} p<0.05$.

constructed using buffered $\mathrm{Zn}^{2+}$ solutions, yielding an $\mathrm{IC}_{50}$ value of $7.0 \pm 0.35 \mathrm{nM}$ for $\mathrm{Zn}^{2+}$ inhibition of homomeric ASICla current $(n=5)$ (Fig. $6 D)$.

The effect of $\mathrm{Zn}^{2+}$ on ASIC currents mediated by heteromeric ASIC1a-ASIC2a was also investigated in CHO cells. To ensure that the current studied is indeed mediated by heteromeric ASIC1a-ASIC2a channels, the following two criteria were used: (1) $\mathrm{pH}$ dose-response demonstrated a $\mathrm{pH}_{0.5}$ of $\sim 5.5$ (Fig. $6 E$ ), which is different from the values for homomeric ASICla and homomeric ASIC2a channels and close to the reported $\mathrm{pH}_{0.5}$ value for heteromeric ASIC1a-ASIC2a channels expressed in Xenopus oocytes (Baron et al., 2001); (2) current can be potentiated by $100-300 \mu \mathrm{M} \mathrm{Zn}{ }^{2+}$, a characteristic for ASIC2a-containing 
channels (Fig. 6F). Similar to homomeric ASIC1a current, current mediated by heteromeric ASIC1a-ASIC2a channels was also potentiated by TPEN (Fig. $6 F, G$ ). Detailed dose-response analysis yielded an $\mathrm{IC}_{50}$ value of $10.04 \pm 1.23 \mathrm{~nm}(n=6)$ for $\mathrm{Zn}^{2+}$ inhibition of ASIC1a-ASIC2a current (Fig. $6 H$ ).

\section{Involvement of extracellular lysine in} high-affinity $\mathrm{Zn}^{2+}$ inhibition of the ASIC current

Based on the finding that ASIC1a is the specific subunit conferring high-affinity $\mathrm{Zn}^{2+}$ inhibition and that inhibition is likely caused by $\mathrm{Zn}^{2+}$ binding to the extracellular site(s) of the channels, we performed site-directed mutagenesis studies to identify specific amino acid(s) involved in the high-affinity $\mathrm{Zn}^{2+}$ inhibition. In most proteins, $\mathrm{Zn}^{2+}$ is usually coordinated by nitrogen, sulfur, or oxygen atoms found in the side chains of cysteine, glutamate, and histidine residues (Glusker, 1991; Fayyazuddin et al., 2000). In addition, lysine, a positive charged residue, has also been reported to be involved in highaffinity $\mathrm{Zn}^{2+}$ modulation of NMDA channels (Fayyazuddin et al., 2000). Based on these factors, the following amino acids located in the extracellular domain between the first and second transmem-

brane segments of the ASICla subunit were considered as potential targets: C61, E97, E123, H173, and K133. Sequence alignment demonstrated that these residues are found only in ASICla but not ASIC1 $\beta$, ASIC2a, and ASIC3 in the comparable positions (Fig. 7A). Noncharged residues were replaced with alanine (i.e., C61A, E97A, E123A, and H173A), whereas positive charged K133 was replaced with arginine (K133R). Mutations were screened by measuring the potentiation of ASIC current by $10 \mu \mathrm{M}$ TPEN followed by detailed $\mathrm{Zn}^{2+}$ dose-inhibition analysis. When expressed in $\mathrm{CHO}$ cells, all mutants showed a normal response to $\mathrm{pH}$ drops with similar $\mathrm{pH}_{0.5}$ and amiloride blockade as the wildtype ASICla (data not shown).

As shown in Figure 7, mutations of C61, E97, E123, or H173 to alanine (A) did not significantly affect the potentiation of ASIC current by $10 \mu \mathrm{M}$ TPEN (Fig. $7 B, C)(n=5-9)$; however, mutation of K133 to arginine (R) completely abolished the TPEN potentiation (Fig. $7 B, C)(n=15)$. Consistent with potentiation by TPEN, addition of $10 \mathrm{nM}$ buffered $\mathrm{Zn}^{2+}$ inhibited the current mediated by wild-type ASIC1a, C61A, E97A, E123A, and H173A mutants by $50-60 \%$ (Fig. $8 A, B$ ); however, addition of buffered $\mathrm{Zn}^{2+}$ to as high as $1 \mu \mathrm{M}$ did not inhibit the ASIC current mediated by K133R mutant $(n=6)$ (Fig. $8 C, D)$.

\section{$\mathrm{Zn}^{2+}$ chelation potentiates ASIC-mediated intracellular $\mathrm{Ca}^{2+}$ increase and membrane depolarization}

Increased intracellular $\mathrm{Ca}^{2+}$ concentration $\left(\left[\mathrm{Ca}^{2+}\right]_{\mathrm{i}}\right)$ is critical for normal neuronal function and neuronal injury in various neurological conditions. Previous studies have shown that activation of ASICs induced substantial increase of $\left[\mathrm{Ca}^{2+}\right]_{i}$ in cortical neurons, and the entry of $\mathrm{Ca}^{2+}$ through ASICs is responsible to a large extent for glutamate receptor-independent, acidosis- mediated ischemic neuronal injury (Xiong et al., 2004). To know whether high-affinity $\mathrm{Zn}^{2+}$ modulation of ASICs also affects acid-induced $\mathrm{Ca}^{2+}$ entry into neurons, we performed $\mathrm{Ca}^{2+}$ imaging experiments to study the effect of $\mathrm{Zn}^{2+}$ chelation on ASIC-mediated $\left[\mathrm{Ca}^{2+}\right]_{\mathrm{i}}$ increase. In the majority of cortical neurons, reduction of $\mathrm{pH}_{\mathrm{o}}$ to 6.5 in the presence of blockers of voltage-gated $\mathrm{Ca}^{2+}$ channels (e.g., $5 \mu \mathrm{M}$ nimodipine and $3 \mu \mathrm{M}$ $\omega$-conotoxin MVIIC) and glutamate receptors (10 $\mu \mathrm{M}$ MK801 and $20 \mu \mathrm{M}$ CNQX) induced a substantial increase in $\left[\mathrm{Ca}^{2+}\right]_{\mathrm{i}}$, as indicated by an increase in the intensity of $340 / 380 \mathrm{~nm}$ ratio image. This acid-induced $\mathrm{Ca}^{2+}$ increase can be blocked by the ASIC blocker amiloride and venom of the tarantula Psalmopoeus cambridgei (PcTX venom) (Xiong et al., 2004). Because the majority of voltage-gated $\mathrm{Ca}^{2+}$ channels and glutamate receptors are already blocked, the increase of $\left[\mathrm{Ca}^{2+}\right]_{\mathrm{i}}$ by lowering $\mathrm{pH}$ should be caused to a large extent by direct activation of ASICs. Bath perfusion of TPEN $(3 \mu \mathrm{M})$ did not affect baseline $\left[\mathrm{Ca}^{2+}\right]$; however, it dramatically potentiated the acid-induced increase of $\left[\mathrm{Ca}^{2+}\right]_{\mathrm{i}}(340 / 380 \mathrm{~nm}$ ratio before TPEN: $1.52 \pm 0.19$; after $3 \mu \mathrm{M}$ TPEN: $2.14 \pm 0.27 ; n=15 ; p<0.01$ ) (Fig. 9).

In addition to an increase of $\left[\mathrm{Ca}^{2+}\right]_{\mathrm{i}}$ through ASICs, activation of ASICs has been shown to induce membrane depolarization in hippocampal and retinal ganglion neurons (Baron et al., 2002; Lilley et al., 2004). Membrane depolarization by ASIC activation is believed to facilitate glutamate receptor-mediated excitatory neurotransmission (Wemmie et al., 2002). Our next experiment was to determine whether high-affinity $\mathrm{Zn}^{2+}$ modulation of ASICla-containing channels has any impact on membrane depolarization induced by ASIC activation in cortical neurons. Current-clamp experiments were performed to record membrane potential as described previously (Xiong et al., 1997). As shown in Figure 10, a moderate de- 
A

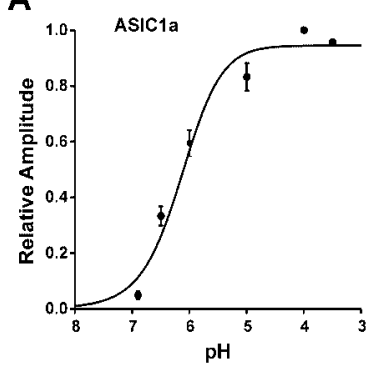

C

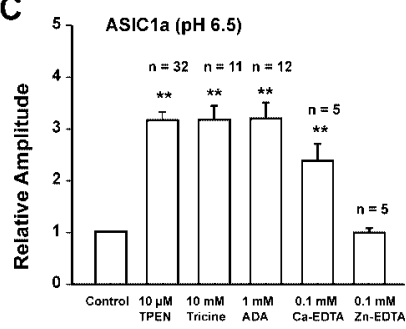

E
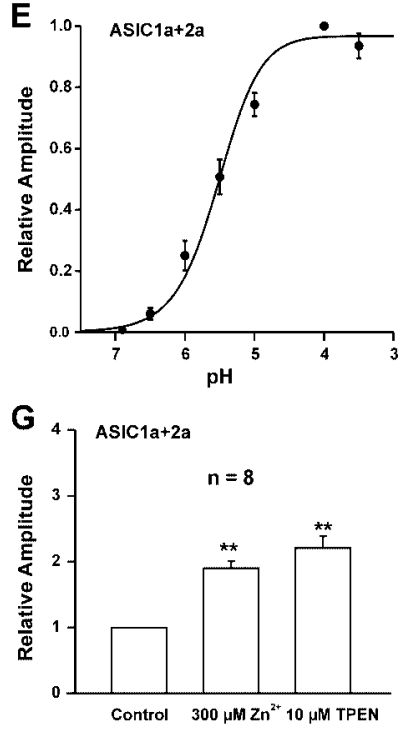

B

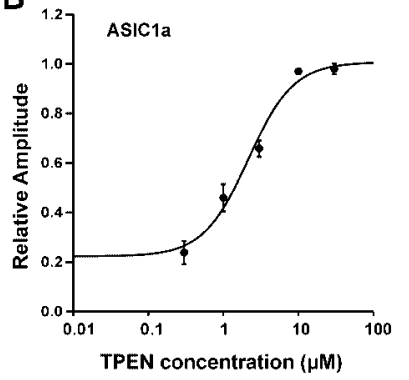

D

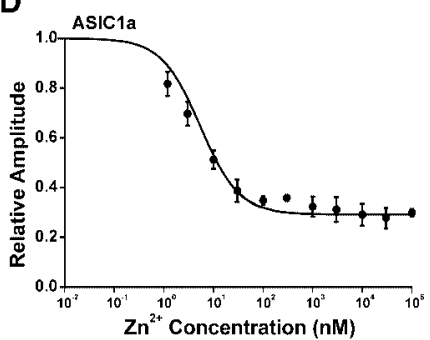

$\mathbf{F}$
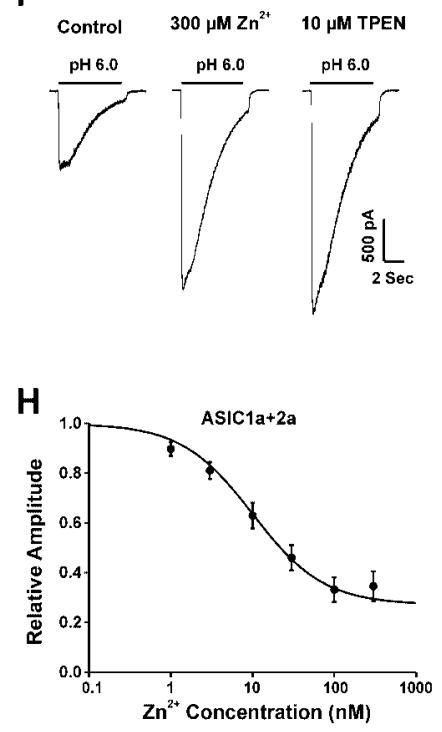

Figure 6. Detailed high-affinity $\mathrm{Zn}^{2+}$ modulation of ASIC current mediated by homomeric ASIC1a and heteromeric ASIC1a-ASIC2a channels expressed in $\mathrm{CHO}^{\mathrm{C}}$ cells. $A$, pH dose-response curve for homomeric ASIC1a channels in $\mathrm{CHO}_{0}$ cells with $\mathrm{pH}_{0.5}$ of $6.15 \pm 0.08 ; n=5$. B, Dosedependent potentiation of ASIC1a current in $\mathrm{CH} 0$ cells by TPEN with an $\mathrm{EC}_{50}$ value of $1.4 \pm 0.02$ $\mu \mathrm{m} ; n=5$. C, In addition to being potentiated by TPEN $(n=32)$, which is membrane permeable, homomeric ASIC1a current in $\mathrm{CHO}$ cells was also potentiated by membrane-impermeable $\mathrm{Zn}^{2+}$ chelators such as ADA and $\mathrm{Ca}^{2+}-$ EDTA $(n=5-12)$. The ASIC 1 a current was not potentiated by $\mathrm{Zn}^{2+}$-EDTA, an agent that chelates other heavy-metal ions but not $\mathrm{Zn}^{2+} ;{ }^{* *} p<$ 0.01. D, Dose-dependent inhibition of ASIC1a current in $\mathrm{CH}_{0}$ cells by buffered $\mathrm{Zn}^{2+}$ with an $\mathrm{IC}_{50}$ value of $7.0 \pm 0.35 \mathrm{~nm} ; n=5$. E, pH dose-response curve for ASIC1a-ASIC2a channels in CHO cells with $\mathrm{pH}_{0.5}$ of $5.53 \pm 0.24 ; n=3$. F, Representative traces showing TPEN potentiation of the ASIC1a-ASIC2a current in CHO cells. As expected for ASIC1a-ASIC2a channels, ASIC currents in these cells were also potentiated by $300 \mu \mathrm{m} Z \mathrm{n}^{2+}$. G, Summary data from eight cells showing the potentiation of ASIC1a-ASIC2a current by $10 \mu \mathrm{M}$ TPEN $(2.23 \pm 0.11$-fold $)$ and $300 \mu \mathrm{M}$ $\mathrm{Zn}^{2+}\left(1.90 \pm 0.07\right.$-fold); ${ }^{* *} p<0.01$. H, Dose-dependent inhibition of ASIC1a-ASIC2a current in CHO cells by buffered $\mathrm{Zn}^{2+}$ with an $\mathrm{IC}_{50}$ value of $10.04 \pm 1.23 \mathrm{~nm} ; n=6$.

crease of $\mathrm{pH}_{\mathrm{o}}$ from 7.4 to 7.0 , which is expected to activate a small inward current under voltage-clamp conditions, induced a significant membrane depolarization from a holding potential of -60 to $-39.2 \pm 1.5 \mathrm{mV}(n=5 ; p<0.01)$. This depolarization was recorded in the presence of blockers of voltage-gated $\mathrm{Ca}^{2+}$ channels (e.g., 5 $\mu \mathrm{M}$ nimodipine) and glutamate receptor-gated channels (10 $\mu \mathrm{M} \mathrm{MK}$

801 and $20 \mu \mathrm{M}$ CNQX); therefore, it is not caused by a secondary activation of these channels. Chelation of contaminating $\mathrm{Zn}^{2+}$ by TPEN dramatically potentiated membrane depolarization to $-12.0 \pm 1.4 \mathrm{mV}(n=5 ; p<0.01)$, indicating a strong tonic inhibition on ASIC-mediated membrane depolarization by nanomolar $\mathrm{Zn}^{2+}$.

\section{Discussion}

ASICs are abundant in peripheral sensory and central neurons. Activation of ASICs in sensory neurons may participate in nociception, mechanosensation, and taste transduction. Activation of ASIC1a in central neurons is involved in synaptic transmission, learning, and memory. In pathological conditions including brain ischemia, activation of ASICla is involved in glutamateindependent $\mathrm{Ca}^{2+}$ toxicity (Xiong et al., 2004). In the present study, we demonstrated that the activities of ASICs in central neurons are negatively modulated by the endogenous transition metal ion $\mathrm{Zn}^{2+}$ at nanomolar concentrations. This high-affinity $\mathrm{Zn}^{2+}$ inhibition is ASICla specific. Site-directed mutagenesis demonstrated that K133, a positively charged amino acid located in the extracellular domain of the ASIC1a subunit, is involved in high-affinity $\mathrm{Zn}^{2+}$ binding to the channel.

The first evidence that nanomolar $\mathrm{Zn}^{2+}$ inhibits ASICs came from the finding that removal of contaminating $\mathrm{Zn}^{2+}$ from extracellular solutions dramatically increased the amplitude of ASIC currents in mouse cortical neurons. Because most physiological solutions contain contaminating concentrations of free $\mathrm{Zn}^{2+}$ from 20 to $50 \mathrm{nM}$ (Paoletti et al., 1997; Amar et al., 2001), potentiation of the ASIC current by $\mathrm{Zn}^{2+}$ chelation indicates that ASICs are tonically inhibited by $\mathrm{Zn}^{2+}$ at nanomolar concentrations. The finding that both the membrane-impermeable $\mathrm{Zn}^{2+}$ chelators (EDTA, ADA, and DTPA) and the membranepermeable chelator (TPEN) had a similar effect on the current suggests that $\mathrm{Zn}^{2+}$ inhibition occurs at the extracellular side of the membrane. More direct evidence supporting the presence of high-affinity $\mathrm{Zn}^{2+}$ inhibition at extracellular site(s) came from the finding that addition of nanomolar concentrations of buffered $\mathrm{Zn}^{2+}$ to the extracellular solution dose-dependently inhibited the ASIC current.

Homomeric ASIC1a and heteromeric ASIC1a-ASIC2a channels are the most common configurations of ASICs in CNS neurons (Baron et al., 2002; Askwith et al., 2004). Our studies in neurons from ASIC1 $-/-$ and ASIC2- $-1-$ mice demonstrated that the absence of the ASIC2 subunit did not affect the $\mathrm{Zn}^{2+}$ inhibition of ASIC currents, whereas deletion of the ASIC1 gene completely eliminated the $\mathrm{Zn}^{2+}$ inhibition. Dependence on the ASICla subunit for $\mathrm{Zn}^{2+}$ inhibition was further confirmed by the finding that $\mathrm{Zn}^{2+}$ inhibits only the current mediated by homomeric ASIC1a or heteromeric ASIC1a-ASIC2a channels expressed in CHO cells, without any effect on currents mediated by homomeric ASIC1 $\beta$, ASIC2a, or ASIC3.

In most proteins, $\mathrm{Zn}^{2+}$ is coordinated by nitrogen, sulfur, or oxygen atoms in the side chains of histidine, cysteine, or glutamate residues (Glusker, 1991; Fayyazuddin et al., 2000). In addition, participation of lysine as a direct coordinating group has been demonstrated in the binuclear metal centers of several $\mathrm{Zn}^{2+}$-containing enzymes. Mutation of histidine(s), for example, is known to affect $\mathrm{Zn}^{2+}$ modulation of several ion channels (Horenstein and Akabas, 1998; Harvey et al., 1999; Fayyazuddin et al., 2000; Dunne et al., 2002). Similarly, mutation of lysine has been shown to abolish high-affinity $\mathrm{Zn}^{2+}$ inhibition of NMDA channels (Fayyazuddin et al., 2000). Based on the evidence that $\mathrm{Zn}^{2+}$ inhibition of the ASIC current occurs at an extracellular site 
or sites and that the inhibition is ASICla dependent, we performed single point mutations targeting potential $\mathrm{Zn}^{2+}$ binding site(s) unique to the ASICla subunit. Mutation of C61, E97, E123, and H173 did not significantly affect the $\mathrm{Zn}^{2+}$ inhibition of the ASICla current; however, mutation of K133 to R completely eliminated the $\mathrm{Zn}^{2+}$ inhibition. It is not clear whether lysine is directly involved or closely associated with the high-affinity $\mathrm{Zn}^{2+}$ binding site(s). Our findings suggest, however, that electrical repulsion may not be a mechanism for $\mathrm{Zn}^{2+}$ inhibition because replacing lysine with similarly charged arginine eliminated the $\mathrm{Zn}^{2+}$ effect.

The inhibition of ASIC currents by $\mathrm{Zn}^{2+}$ shares some similarity to $\mathrm{Zn}^{2+}$ modulation of NMDA channels (Chen et al., 1997; Paoletti et al., 1997; Fayyazuddin et al., 2000): (1) both inhibitions take place at nanomolar concentrations; (2) both inhibitions are partial, with maximal inhibition reached at $70-$ $80 \%$; (3) both inhibitions are voltage independent; and (4) at least one positively charged residue (K133 for ASIC and K233 for NMDA channel) is involved.

The reported concentration of free $\mathrm{Zn}^{2+}$ in physiological fluids is quite low. In equine and bovine plasma, for example, free $\mathrm{Zn}^{2+}$ is reported to be $<0.5 \mathrm{~nm}$ (Magneson et al., 1987; Zhang and Allen, 1995). In the CNS, $\mathrm{Zn}^{2+}$ is sequestered in vesicles at glutamatergic nerve terminals and can be released into the synaptic cleft during excitatory stimulation (Smart et al., 1994). The exact level of free $\mathrm{Zn}^{2+}$ in the synaptic cleft is not known and difficult to deduce. For high-affinity $\mathrm{Zn}^{2+}$ inhibition to play a dynamic role in synaptic transmission, the extracellular free $\mathrm{Zn}^{2+}$ needs to be reduced to below $10 \mathrm{~nm}$ after its release. This would require the presence of a high-affinity $\mathrm{Zn}^{2+}$ uptake system. Recent cloning of $\mathrm{Zn}^{2+}$ transporters in mammalian brains (Palmiter and Findley, 1995) and the finding of both high- and low-affinity $\mathrm{Zn}^{2+}$ uptake mechanisms at neuronal presynaptic terminals (Howell et al., 1984; Wensink et al., 1988; Palmiter et al., 1996a,b) strongly suggest that a dynamic change in $\mathrm{Zn}^{2+}$ concentration in the nanomolar range might be possible.

Mild acidosis and moderate activation of ASICs is expected to induce membrane depolarization and facilitate glutamate receptor-mediated excitatory neurotransmission (Baron et al., 2002; Wemmie et al., 2002; Lilley et al., 2004). Our data show that in mouse cortical neurons, decreasing $\mathrm{pH}$ to 7.0 induced a membrane depolarization of $\sim 20 \mathrm{mV}$. With $\mathrm{Zn}^{2+}$ chelated by TPEN, the same $\mathrm{pH}$ decrease induced a depolarization of up to $50 \mathrm{mV}$. This dramatic depolarization should enhance activation of voltage-gated $\mathrm{Ca}^{2+}$ and NMDA channels, thus facilitating excitatory synaptic transmission. Release of $\mathrm{Zn}^{2+}$ and inhibition of ASICs as well as NMDA channels (Westbrook and Mayer, 1987; Peters et al., 1987) therefore may serve as a negative feedback mechanism to maintain neuronal excitation at a moderate level. Consistent with an inhibitory role of synaptically released $\mathrm{Zn}^{2+}$ in neuronal excitation, Cole and colleagues (2000) have demonstrated that $\mathrm{Zn}^{2+}$ transporter 3 knock-out mice, which lack histochemically reactive $\mathrm{Zn}^{2+}$ in synaptic vesicles, were much more

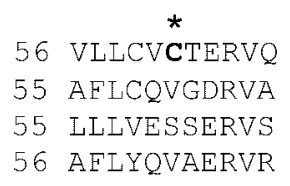

$\begin{array}{cc} & * \\ 91 & \text { TLCNLNEERESQ } \\ 90 & \text { TFCNTNAVRLSQ } \\ 90 & \text { TLCNLNGFRESR } \\ 91 & \text { TLCNINPLRRSR }\end{array}$

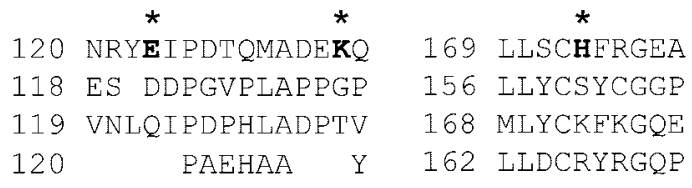

C

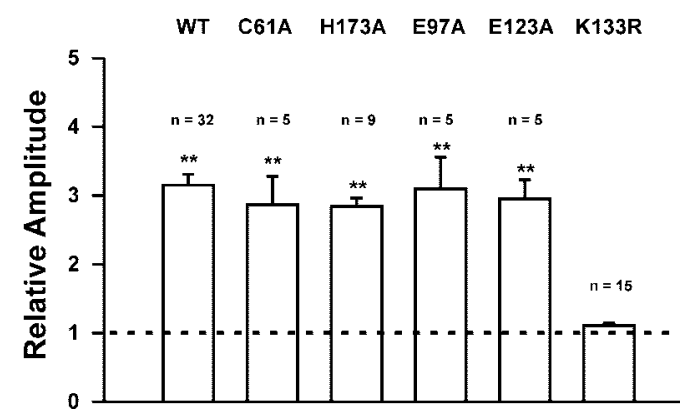

Figure 7. Mutagenesis scan to identify amino acid residues involved in high-affinity $\mathrm{Zn}^{2+}$ inhibition and effect of $\mathrm{Zn}^{2+}$ chelation on ASIC current mediated by various mutant ASIC1a channels expressed in CHO cells. A, Alignment of ASIC1a, ASIC1 $\beta$,

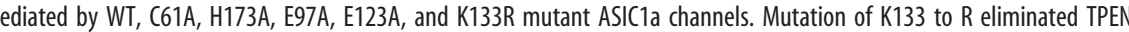
potentiation of the ASIC1a current. C, Summary data showing relative increase in the amplitude of ASIC current mediated by WT ASIC1a and different mutant channels by bath application of $10 \mu \mathrm{M}$ TPEN; $n=5-32 ;{ }^{* *} p<0.01$.

susceptible to kainic acid-induced limbic seizures than wild-type mice. Similarly, studies by Blasco-Ibanez et al. (2004) demonstrated that chelation of synaptic zinc induced overexcitations of hilar mossy cells in rat hippocampus. In pathological conditions such as brain ischemia during which severe acidosis occurs, a moderate increase of $\mathrm{Zn}^{2+}$ in the extracellular space may serve as a neuroprotective measure through its inhibition of ASICs and NMDA channels. In contrast, abnormal increase of extracellular $\mathrm{Zn}^{2+}$ is reported to be neurotoxic (Choi et al., 1988; Koh and Choi, 1994) because of the entry of $\mathrm{Zn}^{2+}$ into neurons (Koh et al., 1996).

Similar to central neurons, ASIC1a is highly expressed in sensory neurons where ASICs function in nociception. High-affinity $\mathrm{Zn}^{2+}$ inhibition of ASICla-containing channels therefore may have an impact on pain sensation. Consistent with this idea, it has been shown recently that chelation of $\mathrm{Zn}^{2+}$ in spinal cord fluid produced hyperalgesia, whereas $\mathrm{Zn}^{2+}$ injection produced an antinociceptive effect (Larson and Kitto, 1997). In addition, Izumi and colleagues (1995) demonstrated that $\mathrm{Zn}^{2+}$ deficiency in rats caused sensitization of nociceptive C-fibers. Although inhibition of NMDA channels could be a potential mechanism underlying some of the $\mathrm{Zn}^{2+}$ effects, it is reasonable to speculate that inhibition of ASICs may be an alternative explanation for the $\mathrm{Zn}^{2+}$ mediated antinociceptive effect.

Our studies suggest that $\mathrm{Zn}^{2+}$ differentially modulates the activities of homomeric ASIC1a and heteromeric ASIC1aASIC2a channels. For homomeric ASIC1a channels, $\mathrm{Zn}^{2+}$ has only an inhibitory effect through its interaction with the highaffinity binding site(s) (involving K133) on the ASIC1a subunit, resulting in reduced proton binding to the channel. For ASIC1a- 

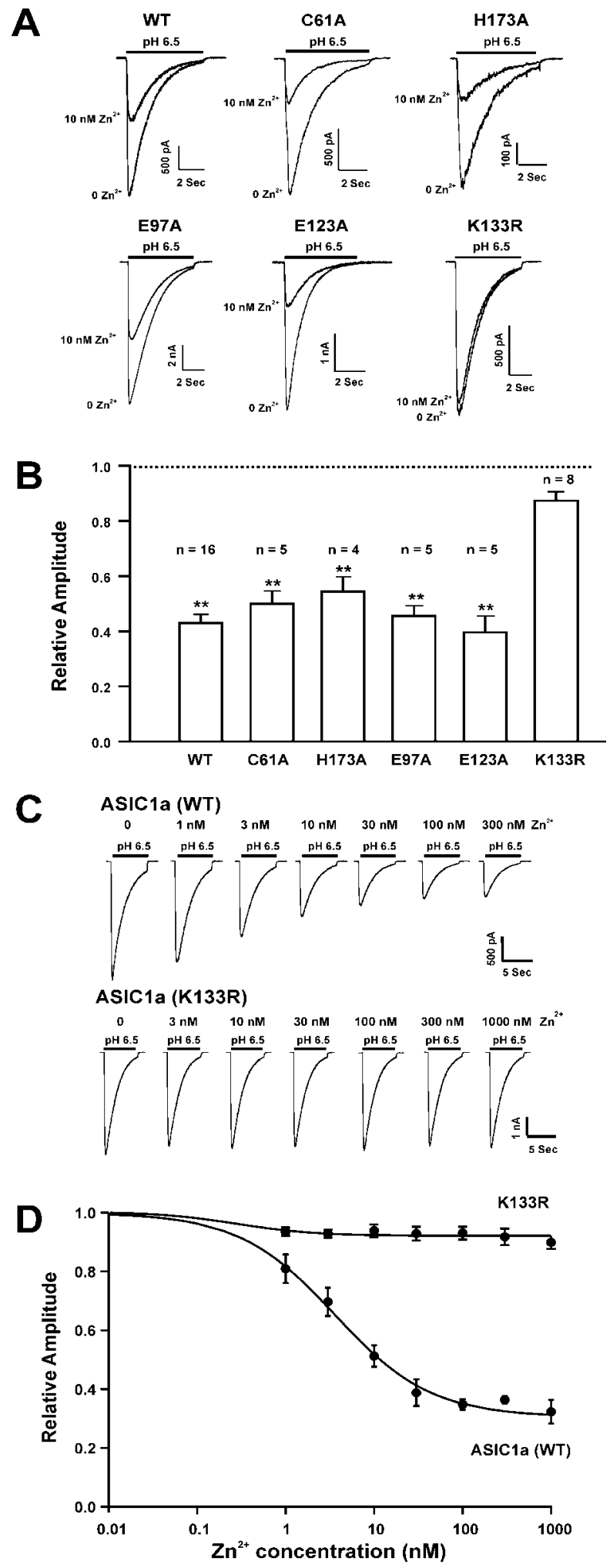

Figure 8. Effect of buffered $\mathrm{Zn}^{2+}$ on ASIC current mediated by WT and mutant ASIC1a channels in CHO cells. A, Representative traces showing inhibition by $10 \mathrm{~nm}$ free $\mathrm{Zn}^{2+}$ on ASIC current mediated by WT, C61A, H173A, E97A, E123A, and K133R mutant ASIC1a channels expressed in $\mathrm{CHO}$ cells. Mutation of $\mathrm{K} 133$ to $\mathrm{R}$ eliminated $\mathrm{Zn}^{2+}$ inhibition of ASIC1a current. $B$, Relative amplitude of ASIC1a current mediated by WT and different mutant ASIC1a channels in the presence of $10 \mathrm{~nm}$ free $Z \mathrm{n}^{2+} ; n=4-16 . C, D$, Dose-dependent inhibition of WT and K133R mutant ASIC1a channels by buffered $\mathrm{Zn}^{2+} . \mathrm{Zn}^{2+}$ inhibits the current mediated by WT ASIC1a channels with an $\mathrm{IC}_{50}$ value of $7.0 \pm 0.35 \mathrm{~nm}(n=5)$; however, it has no inhibition on K133R mutant channels with concentrations as high as $1000 \mathrm{~nm}(n=6) ;{ }^{* *} p<0.01$.
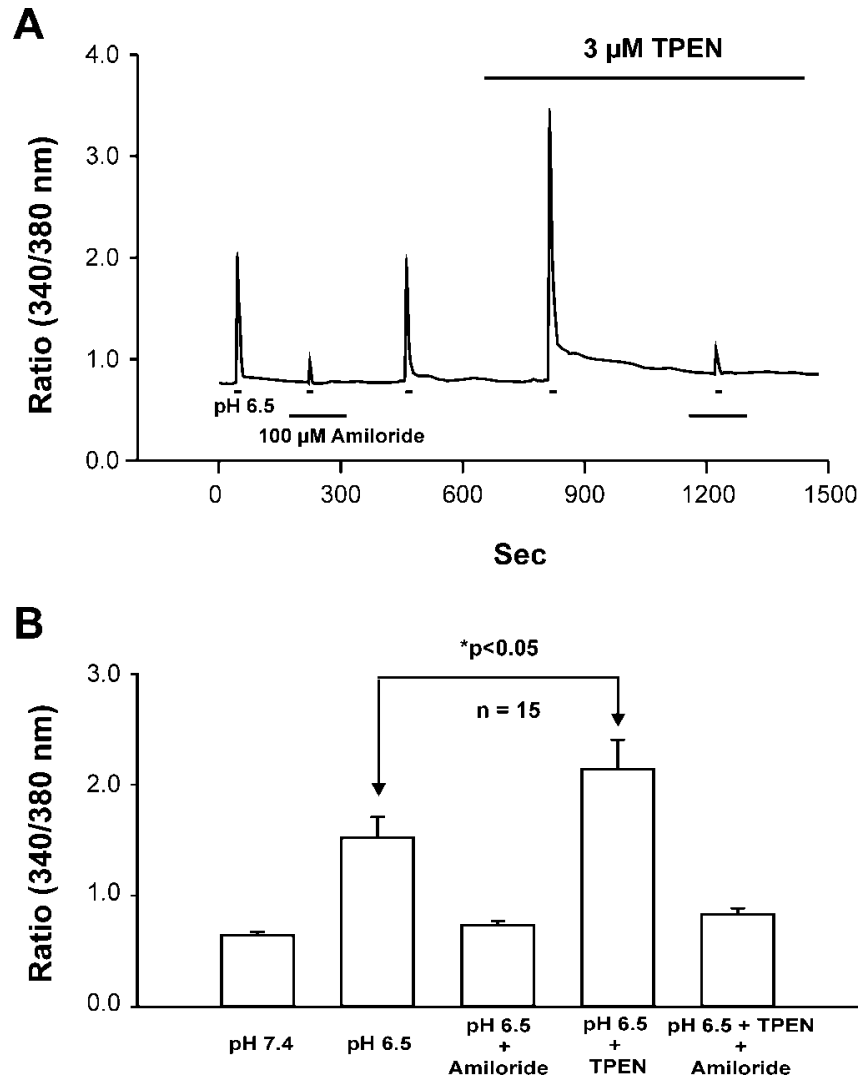

Figure 9. Chelation of contaminating $\mathrm{Zn}^{2+}$ potentates acid-induced increases in $\left[\mathrm{Ca}^{2+}\right]_{\mathrm{i}}$ in cortical neurons. A, Representative $340 / 380 \mathrm{~nm}$ ratio demonstrating changes in $\left[\mathrm{Ca}^{2+}\right]_{\mathrm{i}}$ induced by $\mathrm{pH}$ decrease in the absence and presence of $3 \mu \mathrm{m}$ TPEN. Amiloride $(100 \mu \mathrm{m})$ almost completely blocked $\left[\mathrm{Ca}^{2+}\right]_{\mathrm{i}}$ increase by low $\mathrm{pH}$ in both the absence and presence of TPEN. $B$, Summary data demonstrating increase in $340 / 380 \mathrm{~nm}$ ratio by $\mathrm{pH}$ decrease in the absence and presence of TPEN; $n=15$. To block potential $\mathrm{Ca}^{2+}$ entry through glutamate receptors and voltage-gated $\mathrm{Ca}^{2+}$ channels, $10 \mu \mathrm{M}$ MK801, $20 \mu \mathrm{M}$ CNQX, and $5 \mu \mathrm{m}$ nimodipine were included in all solutions.
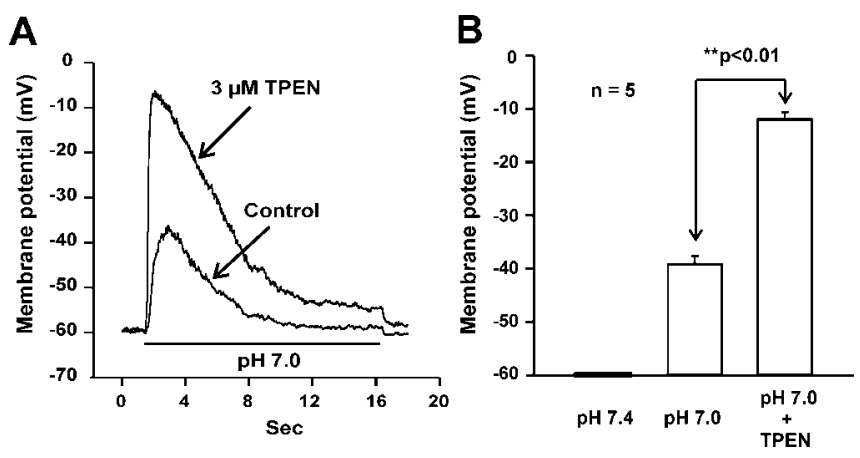

Figure 10. $\quad \mathrm{Zn}^{2+}$ chelation potentates acid-induced membrane depolarization in cultured mouse cortical neurons. A, Representative traces showing membrane depolarization induced by $\mathrm{pH}$ reduction from 7.4 to 7.0 in the absence and presence of TPEN ( $3 \mu \mathrm{M})$. B, Summary data showing the amplitude of membrane depolarization induced by $\mathrm{pH}$ reduction before and after $3 \mu \mathrm{M}$ TPEN. To block secondary activation of glutamate receptors and voltage-gated $\mathrm{Ca}^{2+}$ channels, $10 \mu \mathrm{M}$ MK801, $20 \mu \mathrm{M}$ CNQX, and $5 \mu \mathrm{m}$ nimodipine were included in all solutions.

ASIC2a channels, however, a complex bidirectional modulation by $\mathrm{Zn}^{2+}$ exists. At low nanomolar concentrations, $\mathrm{Zn}^{2+}$ inhibits the channel by binding to a high-affinity site on the ASIC1a subunit. This inhibition saturates at high nanomolar concentrations. As the concentration increases to high micromolar $(\sim 100 \mu \mathrm{M})$, $\mathrm{Zn}^{2+}$ binds to low-affinity site(s) on the ASIC2a subunit (involv- 
ing $\mathrm{H} 162$ and $\mathrm{H} 339$ ), resulting in increased affinity for proton binding and potentiation of ASIC currents (Baron et al., 2001). One alternative explanation, however, could be that binding of $\mathrm{Zn}^{2+}$ to the low-affinity site(s) somehow interferes with the high-affinity binding site, thus reducing $\mathrm{Zn}^{2+}$ inhibition of the ASIC current. This idea is supported by the finding that potentiation of ASIC1a-ASIC2a currents by high concentrations of $\mathrm{Zn}^{2+}$ takes place only in the absence of a $\mathrm{Zn}^{2+}$ chelator. When compared with the amplitude of ASIC currents in the presence of $10 \mu \mathrm{M}$ TPEN, however, the net effect by addition of $300 \mu \mathrm{M} \mathrm{Zn}{ }^{2+}$ is actually a minor reduction of the current (Fig. $6 G$ ).

Different from homomeric ASIC1a, heteromeric ASIClaASIC2a channels do not have substantial $\mathrm{Ca}^{2+}$ permeability. Activation of ASIC1a-ASIC2a channels is therefore unlikely to be directly involved in $\mathrm{Ca}^{2+}$ toxicity. Similar to homomeric ASIC1a channels, however, activation of ASIC1a-ASIC2a is expected to induce membrane depolarization, which may facilitate $\mathrm{Ca}^{2+}$ entry through voltage-gated $\mathrm{Ca}^{2+}$ and NMDA channels. In this regard, high-affinity $\mathrm{Zn}^{2+}$ inhibition of ASIC1a-ASIC2a channels may also play a role in preventing neurons from overexcitation in both physiological and pathological conditions. When the concentration of extracellular $\mathrm{Zn}^{2+}$ reaches high micromolar levels (e.g., $>100 \mu \mathrm{M}$ ), however, an enhancement rather than inhibition of ASIC1a-ASIC2a channels takes place. This enhancement may partially explain the increased neuronal excitation and neurotoxicity seen with nonphysiological high concentrations of extracellular $\mathrm{Zn}^{2+}$ (Choi et al., 1988).

\section{References}

Akopian AN, Chen CC, Ding Y, Cesare P, Wood JN (2000) A new member of the acid-sensing ion channel family. NeuroReport 11:2217-2222.

Allen NJ, Attwell D (2002) Modulation of ASIC channels in rat cerebellar Purkinje neurons by ischemia-related signals. J Physiol (Lond) 543:521-529.

Amar M, Perin-Dureau F, Neyton J (2001) High-affinity Zn block in recombinant $N$-methyl-D-aspartate receptors with cysteine substitutions at the Q/R/N site. Biophys J 81:107-116.

Arslan P, Di Virgilio F, Beltrame M, Tsien RY, Pozzan T (1985) Cytosolic Ca ${ }^{2+}$ homeostasis in Ehrlich and Yoshida carcinomas. A new, membranepermeant chelator of heavy metals reveals that these ascites tumor cell lines have normal cytosolic free $\mathrm{Ca}^{2+}$. J Biol Chem 260:2719-2727.

Askwith CC, Cheng C, Ikuma M, Benson C, Price MP, Welsh MJ (2000) Neuropeptide FF and FMRFamide potentiate acid-evoked currents from sensory neurons and proton-gated DEG/ENaC channels. Neuron 26:133-141.

Askwith CC, Wemmie JA, Price MP, Rokhlina T, Welsh MJ (2004) ASIC2 modulates ASIC1 $\mathrm{H}^{+}$-activated currents in hippocampal neurons. J Biol Chem 279:18296-18305.

Assaf SY, Chung SH (1984) Release of endogenous $\mathrm{Zn}^{2+}$ from brain tissue during activity. Nature 308:734-736.

Baron A, Schaefer L, Lingueglia E, Champigny G, Lazdunski M (2001) Zn ${ }^{2+}$ and $\mathrm{H}^{+}$are coactivators of acid-sensing ion channels. J Biol Chem 276:35361-35367.

Baron A, Waldmann R, Lazdunski M (2002) ASIC-like, proton-activated currents in rat hippocampal neurons. J Physiol (Lond) 539:485-494.

Bassler EL, Ngo-Anh TJ, Geisler HS, Ruppersberg JP, Grunder S (2001) Molecular and functional characterization of acid-sensing ion channel (ASIC) 1b. J Biol Chem 276:33782-33787.

Benos DJ, Stanton BA (1999) Functional domains within the degenerin/ epithelial sodium channel (Deg/ENaC) superfamily of ion channels. J Physiol (Lond) 520:631-644.

Benson CJ, Eckert SP, McCleskey EW (1999) Acid-evoked currents in cardiac sensory neurons: a possible mediator of myocardial ischemic sensation. Circ Res 84:921-928.

Bevan S, Yeats J (1991) Protons activate a cation conductance in a subpopulation of rat dorsal root ganglion neurones. J Physiol (Lond) 433:145-161.

Biagini G, Babinski K, Avoli M, Marcinkiewicz M, Seguela P (2001) Re- gional and subunit-specific downregulation of acid-sensing ion channels in the pilocarpine model of epilepsy. Neurobiol Dis 8:45-58.

Blasco-Ibanez JM, Poza-Aznar J, Crespo C, Marques-Mari AI, Gracia-Llanes FJ, Martinez-Guijarro FJ (2004) Chelation of synaptic zinc induces overexcitation in the hilar mossy cells of the rat hippocampus. Neurosci Lett 355:101-104.

Catarsi S, Babinski K, Seguela P (2001) Selective modulation of heteromeric ASIC proton-gated channels by neuropeptide FF. Neuropharmacology 41:592-600.

Chen CC, England S, Akopian AN, Wood JN (1998) A sensory neuron-specific, proton-gated ion channel. Proc Natl Acad Sci USA 95:10240-10245.

Chen CC, Zimmer A, Sun WH, Hall J, Brownstein MJ, Zimmer A (2002) A role for ASIC3 in the modulation of high-intensity pain stimuli. Proc Natl Acad Sci USA 99:8992-8997.

Chen N, Moshaver A, Raymond LA (1997) Differential sensitivity of recombinant $N$-methyl-D-aspartate receptor subtypes to zinc inhibition. Mol Pharmacol 51:1015-1023.

Choi DW, Yokoyama M, Koh J (1988) Zinc neurotoxicity in cortical cell culture. Neuroscience 24:67-79.

Chu XP, Miesch J, Johnson M, Root L, Zhu XM, Chen D, Simon RP, Xiong ZG (2002) Proton-gated channels in PC12 cells. J Neurophysiol 87:2555-2561.

Chu XP, Zhu XM, Wemmie JA, Price MP, Saugstad JA, Simon RP, Welsh MJ, Xiong ZG (2003a) Subunit-dependent high affinity zinc inhibition of acid-sensing ion channels. Soc Neurosci Abstr 29:308.7.

Chu XP, Zhu XM, Wei WL, Li GH, Simon RP, MacDonald JF, Xiong ZG (2003b) Acidosis decreases low $\mathrm{Ca}^{2+}$-induced neuronal excitation by inhibiting the activity of calcium-sensing cation channels in cultured mouse hippocampal neurons. J Physiol (Lond) 550:385-399.

Cole TB, Robbins CA, Wenzel HJ, Schwartzkroin PA, Palmiter RD (2000) Seizures and neuronal damage in mice lacking vesicular zinc. Epilepsy Res 39:153-169.

Corey DP, Garcia-Anoveros J (1996) Mechanosensation and the DEG/ $\mathrm{ENaC}$ ion channels. Science 273:323-324.

Deval E, Baron A, Lingueglia E, Mazarguil H, Zajac JM, Lazdunski M (2003) Effects of neuropeptide SF and related peptides on acid sensing ion channel 3 and sensory neuron excitability. Neuropharmacology 44:662-671.

De Weille J, Bassilana F, Lazdunski M, Waldmann R (1998) Identification, functional expression and chromosomal localisation of a sustained human proton-gated cation channel. FEBS Lett 433:257-260.

Dunne EL, Hosie AM, Wooltorton JR, Duguid IC, Harvey K, Moss SJ, Harvey RJ, Smart TG (2002) An N-terminal histidine regulates $\mathrm{Zn}^{2+}$ inhibition on the murine GABA(A) receptor beta3 subunit. Br J Pharmacol 137:29-38.

Ettaiche M, Guy N, Hofman P, Lazdunski M, Waldmann R (2004) Acidsensing ion channel 2 is important for retinal function and protects against light-induced retinal degeneration. J Neurosci 24:1005-1012.

Fayyazuddin A, Villarroel A, Le Goff A, Lerma J, Neyton J (2000) Four residues of the extracellular N-terminal domain of the NR2A subunit control highaffinity $\mathrm{Zn}^{2+}$ binding to NMDA receptors. Neuron 25:683-694.

Garcia-Anoveros J, Derfler B, Neville-Golden J, Hyman BT, Corey DP (1997) $\mathrm{BNaC} 1$ and $\mathrm{BNaC} 2$ constitute a new family of human neuronal sodium channels related to degenerins and epithelial sodium channels. Proc Natl Acad Sci USA 94:1459-1464.

Garcia-Anoveros J, Samad TA, Zuvela-Jelaska L, Woolf CJ, Corey DP (2001) Transport and localization of the $\mathrm{DEG} / \mathrm{ENaC}$ ion channel $\mathrm{BNaC} 1 \alpha$ to peripheral mechanosensory terminals of dorsal root ganglia neurons. J Neurosci 21:2678-2686.

Glusker JP (1991) Structural aspects of metal liganding to functional groups in proteins. Adv Protein Chem 42:1-76.

Grunder S, Geissler HS, Bassler EL, Ruppersberg JP (2000) A new member of acid-sensing ion channels from pituitary gland. NeuroReport 11:1607-1611.

Harvey RJ, Thomas P, James CH, Wilderspin A, Smart TG (1999) Identification of an inhibitory $\mathrm{Zn}^{2+}$ binding site on the human glycine receptor alpha1 subunit. J Physiol (Lond) 520:53-64.

Horenstein J, Akabas MH (1998) Location of a high affinity $\mathrm{Zn}^{2+}$ binding site in the channel of alphalbetal gamma-aminobutyric acidA receptors. Mol Pharmacol 53:870-877.

Howell GA, Welch MG, Frederickson CJ (1984) Stimulation-induced uptake and release of zinc in hippocampal slices. Nature 308:736-738.

Immke DC, McCleskey EW (2001) Lactate enhances the acid-sensing $\mathrm{Na}^{+}$ channel on ischemia-sensing neurons. Nat Neurosci 4:869-870.

Izumi H, Mori H, Uchiyama T, Kuwazuru S, Ozima Y, Nakamura I, Taguchi 
S (1995) Sensitization of nociceptive C-fibers in zinc-deficient rats. Am J Physiol 268:R1423-R1428.

Johnson MB, Jin K, Minami M, Chen D, Simon RP (2001) Global ischemia induces expression of acid-sensing ion channel $2 \mathrm{a}$ in rat brain. J Cereb Blood Flow Metab 21:734-740.

Koh JY, Choi DW (1994) Zinc toxicity on cultured cortical neurons: involvement of N-methyl-D-aspartate receptors. Neuroscience 60:1049-1057.

Koh JY, Suh SW, Gwag BJ, He YY, Hsu CY, Choi DW (1996) The role of zinc in selective neuronal death after transient global cerebral ischemia. Science 272:1013-1016.

Krishtal O (2003) The ASICs: signaling molecules? Modulators? Trends Neurosci 26:477-483.

Krishtal OA, Pidoplichko VI (1981) A receptor for protons in the membrane of sensory neurons may participate in nociception. Neuroscience 6:2599-2601.

Larson AA, Kitto KF (1997) Manipulations of zinc in the spinal cord, by intrathecal injection of zinc chloride, disodium-calcium-EDTA, or dipicolinic acid, alter nociceptive activity in mice. J Pharmacol Exp Ther 282:1319-1325.

Lilley S, LeTissier P, Robbins J (2004) The discovery and characterization of a proton-gated sodium current in rat retinal ganglion cells. J Neurosci 24:1013-1022.

Lin W, Ogura T, Kinnamon SC (2002) Acid-activated cation currents in rat vallate taste receptor cells. J Neurophysiol 88:133-141.

Lindemann B (1996) Taste reception. Physiol Rev 76:718-766.

Lingueglia E, De Weille JR, Bassilana F, Heurteaux C, Sakai H, Waldmann R, Lazdunski M (1997) A modulatory subunit of acid sensing ion channels in brain and dorsal root ganglion cells. J Biol Chem 272:29778-29783.

Magneson GR, Puvathingal JM, Ray Jr WJ (1987) The concentrations of free $\mathrm{Mg}^{2+}$ and free $\mathrm{Zn}^{2+}$ in equine blood plasma. J Biol Chem 262:11140-11148.

Mamet J, Baron A, Lazdunski M, Voilley N (2002) Proinflammatory mediators, stimulators of sensory neuron excitability via the expression of acid-sensing ion channels. J Neurosci 22:10662-10670.

McCleskey EW, Gold MS (1999) Ion channels of nociception. Annu Rev Physiol 61:835-856.

Palmiter RD, Findley SD (1995) Cloning and functional characterization of a mammalian zinc transporter that confers resistance to zinc. EMBO J 14:639-649.

Palmiter RD, Cole TB, Quaife CJ, Findley SD (1996a) ZnT-3, a putative transporter of zinc into synaptic vesicles. Proc Natl Acad Sci USA 93:14934-14939.

Palmiter RD, Cole TB, Findley SD (1996b) ZnT-2, a mammalian protein that confers resistance to zinc by facilitating vesicular sequestration. EMBO J 15:1784-1791.

Paoletti P, Ascher P, Neyton J (1997) High-affinity zinc inhibition of NMDA NR1-NR2A receptors. J Neurosci 17:5711-5725.

Peters S, Koh J, Choi DW (1987) Zinc selectively blocks the action of $N$-methyl-D-aspartate on cortical neurons. Science 236:589-593.

Price MP, Snyder PM, Welsh MJ (1996) Cloning and expression of a novel human brain $\mathrm{Na}^{+}$channel. J Biol Chem 271:7879-7882.

Price MP, Lewin GR, McIlwrath SL, Cheng C, Xie J, Heppenstall PA, Stucky CL, Mannsfeldt AG, Brennan TJ, Drummond HA, Qiao J, Benson CJ, Tarr DE, Hrstka RF, Yang B, Williamson RA, Welsh MJ (2000) The mammalian sodium channel BNC1 is required for normal touch sensation. Nature 407:1007-1011.

Price MP, McIlwrath SL, Xie J, Cheng C, Qiao J, Tarr DE, Sluka KA, Brennan TJ, Lewin GR, Welsh MJ (2001) The DRASIC cation channel contributes to the detection of cutaneous touch and acid stimuli in mice. Neuron 32:1071-1083.

Sluka KA, Price MP, Breese NM, Stucky CL, Wemmie JA, Welsh MJ (2003) Chronic hyperalgesia induced by repeated acid injections in muscle is abolished by the loss of ASIC3, but not ASIC1. Pain 106:229-239.

Smart TG, Xie X, Krishek BJ (1994) Modulation of inhibitory and excitatory amino acid receptor ion channels by zinc. Prog Neurobiol 42:393-441.

Sutherland SP, Benson CJ, Adelman JP, McCleskey EW (2001) Acidsensing ion channel 3 matches the acid-gated current in cardiac ischemiasensing neurons. Proc Natl Acad Sci USA 98:711-716.

Ugawa S (2003) Identification of sour-taste receptor genes. Anat Sci Int 78:205-210.

Ugawa S, Ueda T, Ishida Y, Nishigaki M, Shibata Y, Shimada S (2002) Amiloride-blockable acid-sensing ion channels are leading acid sensors expressed in human nociceptors. J Clin Invest 110:1185-1190.

Ugawa S, Yamamoto T, Ueda T, Ishida Y, Inagaki A, Nishigaki M, Shimada S
(2003) Amiloride-insensitive currents of the acid-sensing ion channel-2a (ASIC2a)/ASIC2b heteromeric sour-taste receptor channel. J Neurosci 23:3616-3622.

Varming T (1999) Proton-gated ion channels in cultured mouse cortical neurons. Neuropharmacology 38:1875-1881.

Voilley N (2004) Acid-sensing ion channels (ASICs): new targets for the analgesic effects of non-steroid anti-inflammatory drugs (NSAIDs). Curr Drug Targets Inflamm Allergy 3:71-79.

Waldmann R, Champigny G, Voilley N, Lauritzen I, Lazdunski M (1996) The mammalian degenerin MDEG, an amiloride-sensitive cation channel activated by mutations causing neurodegeneration in Caenorhabditis elegans. J Biol Chem 271:10433-10436.

Waldmann R, Champigny G, Bassilana F, Heurteaux C, Lazdunski M (1997a) A proton-gated cation channel involved in acid-sensing. Nature 386:173-177.

Waldmann R, Bassilana F, de Weille J, Champigny G, Heurteaux C, Lazdunski M (1997b) Molecular cloning of a non-inactivating proton-gated $\mathrm{Na}^{+}$channel specific for sensory neurons. J Biol Chem 272:20975-20978.

Wemmie JA, Chen J, Askwith CC, Hruska-Hageman AM, Price MP, Nolan BC, Yoder PG, Lamani E, Hoshi T, Freeman JH, Welsh MJ (2002) The acid-activated ion channel ASIC contributes to synaptic plasticity, learning, and memory. Neuron 34:463-477.

Wemmie JA, Askwith CC, Lamani E, Cassell MD, Freeman Jr JH, Welsh MJ (2003) Acid-sensing ion channel 1 is localized in brain regions with high synaptic density and contributes to fear conditioning. J Neurosci 23:5496-5502.

Wemmie JA, Coryell MW, Askwith CC, Lamani E, Leonard AS, Sigmund CD, Welsh MJ (2004) Overexpression of acid-sensing ion channel la in transgenic mice increases acquired fear-related behavior. Proc Natl Acad Sci USA 101:3621-3626.

Wensink J, Molenaar AJ, Woroniecka UD, Van den Hamer CJ (1988) Zinc uptake into synaptosomes. J Neurochem 50:782-789.

Westbrook GL, Mayer ML (1987) Micromolar concentrations of $\mathrm{Zn}^{2+}$ antagonize NMDA and GABA responses of hippocampal neurons. Nature 328:640-643.

Wilkins ME, Smart TG (2002) Redox modulation of GABAA receptors obscured by $\mathrm{Zn}^{2+}$ complexation. Neuropharmacology 43:938-944.

Xiong Z, Lu W, MacDonald JF (1997) Extracellular calcium sensed by a novel cation channel in hippocampal neurons. Proc Natl Acad Sci USA 94:7012-7017.

Xiong Z, O’Hanlon D, Becker LE, Roder J, MacDonald JF, Marks A (2000) Enhanced calcium transients in glial cells in neonatal cerebellar cultures derived from S100B null mice. Exp Cell Res 257:281-289.

Xiong ZG, Raouf R, Lu WY, Wang LY, Orser BA, Dudek EM, Browning MD, MacDonald JF (1998) Regulation of $N$-methyl-D-aspartate receptor function by constitutively active protein kinase C. Mol Pharmacol 54:1055-1063.

Xiong ZG, Pelkey KA, Lu WY, Lu YM, Roder JC, MacDonald JF, Salter MW (1999) Src potentiation of NMDA receptors in hippocampal and spinal neurons is not mediated by reducing zinc inhibition. J Neurosci 19:RC37(1-6).

Xiong ZG, Chu XP, MacDonald JF (2001) Effect of Lamotrigine on the $\mathrm{Ca}^{2+}$-sensing cation current in cultured hippocampal neurons. J Neurophysiol 86:2520-2526.

Xiong ZG, Zhu XM, Chu XP, Minami M, Hey J, Wei WL, MacDonald JF, Wemmie JA, Price MP, Welsh MJ, Simon RP (2004) Neuroprotection in ischemia: blocking calcium-permeable acid-sensing ion channels. Cell 118:687-698.

Yermolaieva O, Leonard AS, Schnizler MK, Abboud FM, Welsh MJ (2004) Extracellular acidosis increases neuronal cell calcium by activating acidsensing ion channel 1a. Proc Natl Acad Sci USA 101:6752-6757.

Yiangou Y, Facer P, Smith JA, Sangameswaran L, Eglen R, Birch R, Knowles C, Williams N, Anand P (2001) Increased acid-sensing ion channel ASIC-3 in inflamed human intestine. Eur J Gastroenterol Hepatol 13:891-896.

Zhang P, Allen JC (1995) A novel dialysis procedure measuring free $\mathrm{Zn}^{2+}$ in bovine milk and plasma. J Nutr 125:1904-1910.

Zheng F, Gingrich MB, Traynelis SF, Conn PJ (1998) Tyrosine kinase potentiates NMDA receptor currents by reducing tonic zinc inhibition. Nat Neurosci 1:185-191.

Zhu X, Chu X, Miesch J, Simon R, Xiong Z (2001) Proton-gated channels are involved in acidosis-induced neuronal injury. Soc Neurosci Abstr 27:332.17. 